\title{
Confirmation Of Data-Driven Reservoir Modeling Using Numerical Reservoir Simulation
}

Al Hasan Mohamed Al Haifi

ama0097@mix.wvu.edu

Follow this and additional works at: https://researchrepository.wvu.edu/etd

Part of the Petroleum Engineering Commons

\section{Recommended Citation}

Al Haifi, Al Hasan Mohamed, "Confirmation Of Data-Driven Reservoir Modeling Using Numerical Reservoir Simulation" (2019). Graduate Theses, Dissertations, and Problem Reports. 3835.

https://researchrepository.wvu.edu/etd/3835

This Thesis is protected by copyright and/or related rights. It has been brought to you by the The Research Repository @ WVU with permission from the rights-holder(s). You are free to use this Thesis in any way that is permitted by the copyright and related rights legislation that applies to your use. For other uses you must obtain permission from the rights-holder(s) directly, unless additional rights are indicated by a Creative Commons license in the record and/ or on the work itself. This Thesis has been accepted for inclusion in WVU Graduate Theses, Dissertations, and Problem Reports collection by an authorized administrator of The Research Repository @ WVU. For more information, please contact researchrepository@mail.wvu.edu. 


\title{
CONFIRMATION OF DATA-DRIVEN RESERVOIR MODELING USING NUMERICAL RESERVOIR SIMULATION
}

\author{
Al Hasan Mohamed Mohamed Al Haifi \\ Thesis submitted \\ to the Benjamin M. Statler College of Engineering and Mineral Resources \\ at West Virginia University \\ in partial fulfillment of the requirements for the degree of \\ Master of Science in \\ Petroleum and Natural Gas Engineering
}

Shahab Mohaghegh, Ph.D., Chair

Kashy Aminian, Ph.D.

Sam Ameri, Ph.D.

Department of Petroleum and Natural Gas Engineering

Morgantown, West Virginia

2019

Keywords: Data-Driven Reservoir Modeling, Artificial Intelligence and Data Mining, Top-Down-Model

Copyright 2019, Al Hasan Al Haifi 


\author{
ABSTRACT \\ CONFIRMATION OF DATA-DRIVEN RESERVOIR MODELING \\ USING NUMERICAL RESERVOIR SIMULATION
}

\begin{abstract}
Al Hasan Mohamed Al Haifi
Data driven reservoir modeling, also known as Top-Down Model (TDM), is an alternative to the traditional numerical reservoir simulation technique. Data driven reservoir modeling is a new technology that uses artificial intelligence and machine learning to build full-field reservoir models using field measurements (data - facts) instead of mathematical formulations that represent our current understanding of the physics of the fluid flow through porous media. TDM combines all field measurements into a comprehensive reservoir model to predict the production from each well in a field with multiple wells.

There are many opinions, speculations and criticism about not using the physics-based approach. Therefore, in this thesis, to confirm the capabilities of TDM, synthetic data generated from a numerical reservoir simulation model will be used for the development of a Data Driven Reservoir Model. That means, the physics of the fluid flow through porous media will be modeled using the generated data from the numerical reservoir simulation model which we know everything about.

In order to accomplish the objectives of this thesis a software application will be used for the development of the Top-Down Model. TDM will be developed (trained, calibrated and validated) and history matched using the data generated by a complex numerical reservoir simulation model in order to confirm the capabilities of the TDM in forecasting existing well behavior. Upon Completion of the TDM, predictions will be made using the developed TDM and are tested against the data that will be generated by the numerical reservoir simulation.
\end{abstract}




\section{DEDICATION}

This thesis is dedicated to my parents and my wife, for without their continuous support, none of this would have happened. 


\section{ACKNOWLEDGEMENT}

First of all, I would like to offer my highest gratitude to God the Great for blessing me with the most precious gift - the joy of life, upon which without it, life would be bleak and meaningless.

Completion of this report has made me grateful to a number of persons. Firstly, I would like to express my sincere gratitude to my parents and my wife for providing me a lot of supports. They were always available when I need their help, suggestions and guidelines.

Words cannot express my thanks to my wonderful family for their support during the period of my study and for believing in me and in my work. Special thanks go to the small home in which I spent valuable time learning, improving and expanding my concepts and thoughts, West Virginia University.

I'm so thankful to my advisor Prof. Shahab Mohaghegh for his supervision, advice and guidance from the very early stage of my thesis as well as providing me great experiences throughout this work and of course many thanks to Dr. Kashy Aminian and Dr. Sam Ameri for their continuous support.

Last but not least, I would like to say thank you so much to all my colleagues specially Amir, Ayodeji, and Maher who have given me infinite help, encouragement and strength throughout my thesis in particular and throughout my graduate program in general. 


\section{Table of Contents}

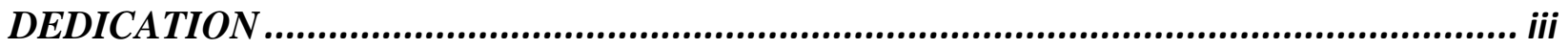

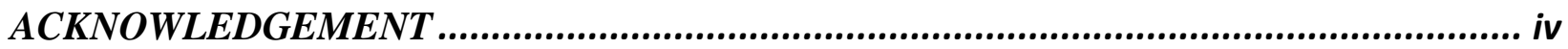

LIST OF FIGURES

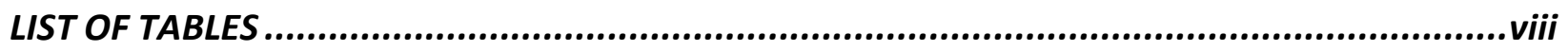

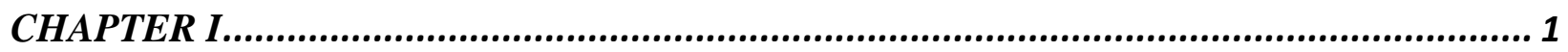

INTRODUCTION ............................................................................................................................................... 1

1.1 GENERAL OVERVIEW .........................................................................................1

1.2 PROBLEM STATEMENT ...........................................................................................3

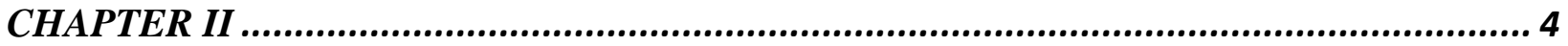

LITERATURE REVIEW ..............................................................................................................................

2.1 DATA-DRIVEN TECHNOLOGIES ……………..................................................................

2.1.1 Data Mining ...........................................................................................................................4

2.1.2 Artificial Intelligence-Based Reservoir Modeling.......................................................................5

2.1.3 Artificial Neural Network .........................................................................................................6

2.2 THE SPATIO-TEMPORAL DATA BASE..................................................................

2.2.1 Static Data .........................................................................................................................................9

2.2.2 Dynamic Data.........................................................................................................................9

2.3 TOP-DOWN MODEL ........................................................................................................ 10

2.3.1 Top-Down Model - Case Studies ...............................................................................................10

2.3.1.1 TDM for Niobrara Field ...............................................................................................................10

2.3.1.2 TDM for Powder River Basin ......................................................................................................13

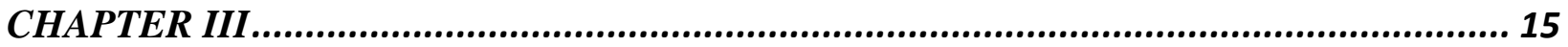

METHODOLOGY ………................................................................................................................. 15

3.1 Introduction ............................................................................................................................ 15

3.2 IMagine Software ................................................................................................................... 16

$3.3 \quad$ Research Strategy ...........................................................................................................................17

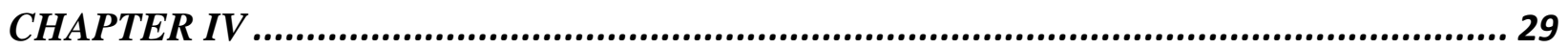

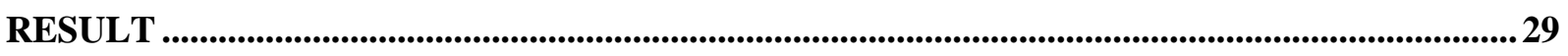

4.1 Training, Calibration and Validation Results.........................................................................29

4.2 Top-Down Model Results (History Matching and TDM Predictions)..................................31

4.3 Confirming Results of TDM Predictions using Numerical Reservoir Simulation data ....35

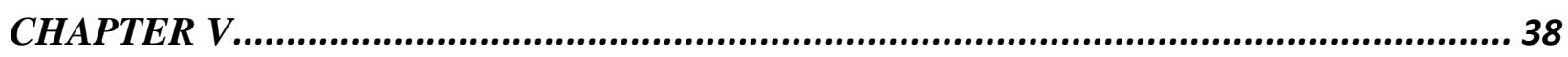




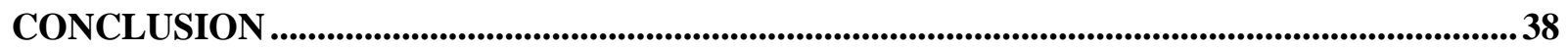

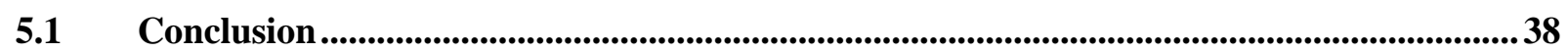

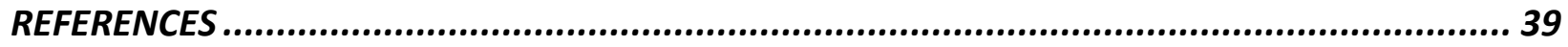




\section{LIST OF FIGURES}

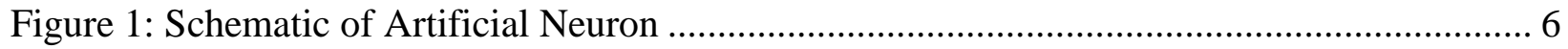

Figure 2: Example of Artificial Neural Network ................................................................... 7

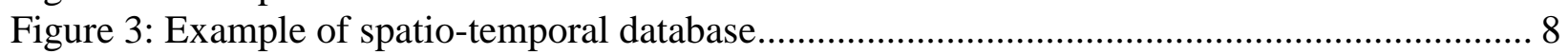

Figure 4: List of inputs (data) for development TDM for Niobrara field .................................... 11

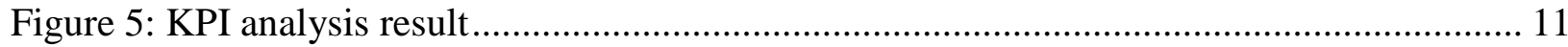

Figure 6: TDM estimations for production history and three years prediction from 2013 for (a)

Entire filed (b, c, d) Different wells ....................................................................................... 12

Figure 7: List of inputs (data) for development TDM for Powder River Basin ........................... 13

Figure 8: TDM estimations for production history and four years prediction from 2013 for the

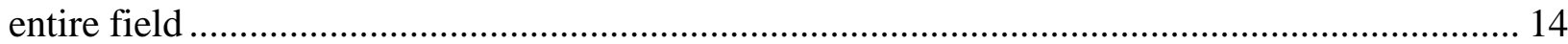

Figure 9: TDM estimations for production history and four years prediction from 2013 for

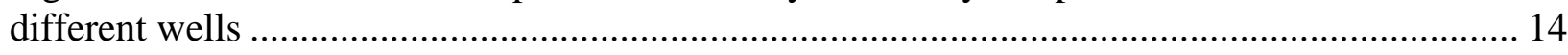

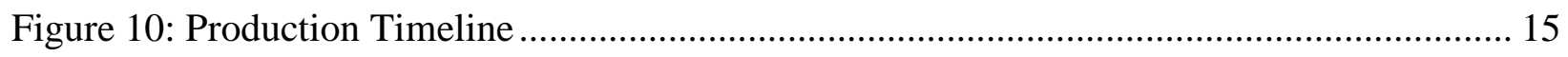

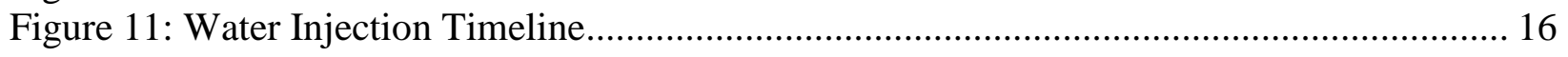

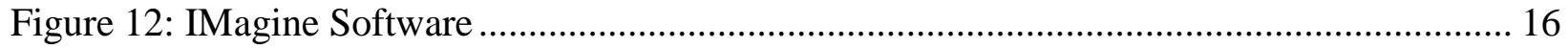

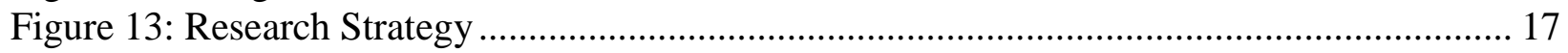

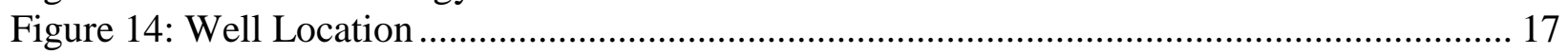

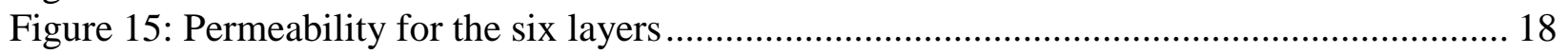

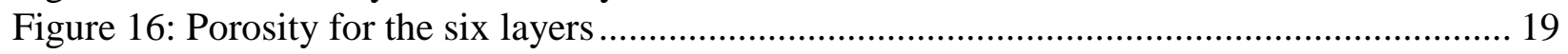

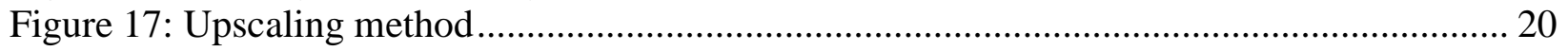

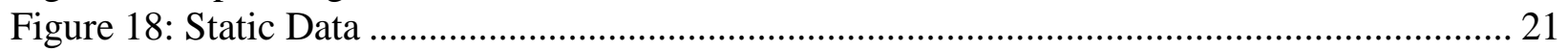

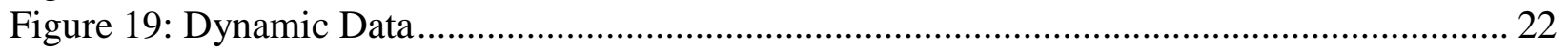

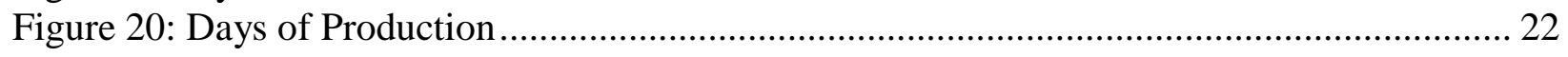

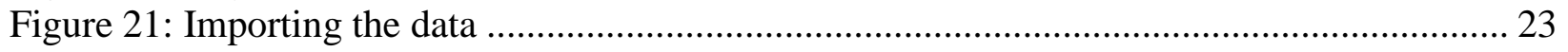

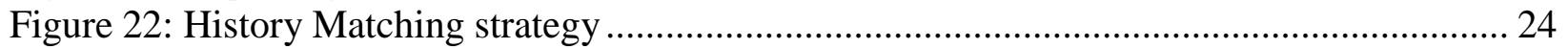

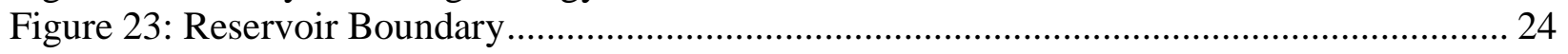

Figure 24: Build and History Match ....................................................................................... 25

Figure 25: Sequences of Top-Down Models (Output) design ...................................................... 26

Figure 26: The attributes that have been selected for building the TDM ..................................... 26

Figure 27: Example of Spatio-Temporal database for Oil .......................................................... 27

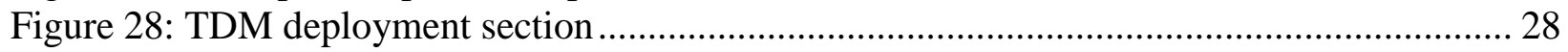

Figure 29: Results of training, calibration validation for Reservoir pressure and water saturation

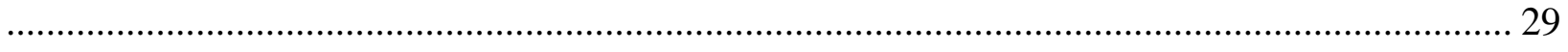

Figure 30: Results of Training, Calibration and Validation for Oil, Gas and Water................... 30

Figure 31: Complete History Matching and Prediction result for well-006 ………….................. 32

Figure 32: Complete History Matching and Prediction result for well-009 ………....................... 32

Figure 33: Complete History Matching and Prediction result for well-021 ………...................... 33

Figure 34: Complete History Matching and Prediction result for well-037 ………..................... 33

Figure 35: Complete History Matching and Prediction results for the entire field (reservoir)..... 34

Figure 36:TDM result versus numerical reservoir simulation result for well-006 ………............. 36

Figure 37: TDM result versus numerical reservoir simulation result for well-009 ...................... 36

Figure 38: TDM result versus numerical reservoir simulation result for well-021 ...................... 37

Figure 39: TDM result versus numerical reservoir simulation result for well-037 ....................... 37 


\section{LIST OF TABLES}

Table 1: Example of the data that included in the Spatio-Temporal Database............................. 8

Table 2: Number of cases in training, calibration and validation ............................................ 27

Table 3: The $\mathrm{R}^{2}$ result for Training, Calibration and Validation datasets ................................ 30 


\section{CHAPTER I}

INTRODUCTION

\subsection{GENERAL OVERVIEW}

In numerical simulation and modeling, the numerical reservoir model is developed using available static and dynamic data. This flow model is based on the geological model. Considering the fact that the geo- cellular model is built using the geological and geophysical data, and then the upscaling process is performed, and the flow model is developed using the well-known engineering fluid flow principles followed by the history matching process, it can be asserted that it is "Bottom-Up" process. (Shahab D. Mohaghegh, S. Alireza Haghighat, Vida Gholami \& David Moreno,, April 2014).

In the traditional reservoir simulation, the major assumption that has to be made is that all the complexities of the reservoir are known and can be modeled in terms of the available mathematical equations. Therefore, if the production does not match the field measurements (observation) that results from the numerical simulation and modeling, it can be concluded that since the reservoir characterization is represented by a geo-cellular (static) model, developed by geoscientists, and is full of interpretations and uncertain values, we as engineers feel comfortable changing these numbers in order to get the match. This problem is even more challenging while dealing with unconventional reservoirs such as Shale. Many engineers believe it would be far from reality when it comes to modeling the physics of what happens in the Shale reservoirs and assert that, the mere reason to use the available models is simply because there is no alternative. (Mohaghegh, S. D., 2011, January) 
Data-driven technologies are a set of new techniques that rely on data rather than our current understanding of the physical phenomena in order to build models, solve problems, and make recommendations and help us make decisions. In the context of reservoir engineering and reservoir modeling, data are also referred to as facts. This is based on the assumption that the measurements made in the field actually represent facts about the reservoir and the state of the fluid flow in it. It is well understood that measurements include noise and that noise, as an integrated part of the collected data, can be handled (Mohaghegh, Data-Driven Reservoir Modeling, 2017).

Data-driven reservoir-modeling development and analysis includes three phases (Mohaghegh, Data-Driven Reservoir Modeling, 2017). The first phase of the data-driven reservoir modeling, which is an exploratory analysis in nature, relates to the data mining. The second phase of data-driven reservoir modeling that is mainly concerned with the development (training, history matching, and validation) of a predictive reservoir model for the entire field is accomplished through artificial intelligence. The final phase of the data-driven reservoir modeling, which is the post-model analysis, includes a combination of both data mining and artificial intelligence. Since data mining is exploratory in nature, it mostly includes unsupervised algorithms. However, in the case of its application to reservoir engineering and reservoir modeling, some of the traditional unsupervised algorithms have been modified in order to incorporate reservoir engineering and geoscience domain expertise in the analysis. 


\subsection{PROBLEM STATEMENT}

In order to efficiently develop and operate a petroleum reservoir, it is important to have a reservoir model. Nowadays, the only technique that is accepted and is being used in our industry is the reservoir numerical simulation. However, this technology is not accurate because it does not use the large amount of the available data from the mature fields. For example, if decline curve analysis is the tool that is being used to make decisions, it is obvious that no reservoir characteristics and no operational constraints are used during the decision-making process. Moreover, this tool is not fast, and it requires significant investment in time and manpower. Therefore, reservoir managers need tools that are accurate and fast in order to make decisions in a timely manner.

Data driven reservoir modeling, also known as Top-Down Model (TDM), provides a complete alternative to the numerical reservoir simulation model and can serve as an appropriate tool for reservoir management. The top-down model is a comprehensive, full-field, empirical reservoir model that does not modify the collection of the measured reservoir characteristics in order to history match multiple independent production variables. Therefore, synthetic data will be used in this study to confirm the capability of the TDM in forecasting existing well behavior. 


\section{CHAPTER II}

\section{LITERATURE REVIEW}

\subsection{DATA-DRIVEN TECHNOLOGIES}

Mohaghegh defined the data-driven modeling as the process of applying artificial intelligence and data mining methods such as machine learning and pattern recognition in order to uncover hidden patterns in large data sets that represent fluid flow in porous media. Then, the discovered patterns are included into a comprehensive and cohesive full-field reservoir model with verifiable forecasting abilities that can be used to manage fields and their production (Mohaghegh, Data-Driven Reservoir Modeling, 2017). Data driven reservoir modeling is a new technology to build reservoir models that represent the fluid flow through porous media using filed measurements. The distinguishing feature of this technology is its data requirement for its analysis. Data-driven technology is completely based on field measurements that include well locations and trajectories, stimulations and completions, core data, well tests, well logs, seismic and production/injection history.

\subsubsection{Data Mining}

Data mining can be defined as the process of extracting a patterns (information) from a large quantities of data sets and transform these patterns into an understandable structure for further use. In data driven reservoir modeling, a comprehensive data set, also known as spatio-temporal database must be made before using any data driven algorithm. The spatio-temporal database should be large enough in order to discover the pattern in the data. Moreover, data cleaning has to be made for the spatio-temporal database to remove the errors, missing records and noise data. 
As mentioned earlier, three phases are included in data-driven reservoir modelling, the first phase is exploratory analysis in nature, relates to the data mining. The second phase includes the development of a predictive reservoir model for the entire field using artificial intelligence. While, the third phase of the data-driven reservoir modelling is the post data analysis that includes a combination of both data mining and artificial intelligence (Mohaghegh, Data-Driven Reservoir Modeling, 2017).

\subsubsection{Artificial Intelligence-Based Reservoir Modeling}

Artificial Intelligence (AI) is a field of computer science which focus on creating machines that can engage on behaviours that humans consider intelligent. Also, artificial intelligence may be defined as a collection of analytic tools that attempts to imitate life. Moreover, Researchers are trying to create systems that can mimic human thoughts. AI is used in areas such as credit card fraud detection, medical diagnosis, bank loan approval, financial portfolio management, selfdriving cars, and many more. AI technology has three main categories; artificial neural networks, fuzzy logic and evolutionary programming. In the oil and gas industry these tools have been used to solve problems related to pressure transient analysis, drilling, reservoir characterization, and well log interpretation (Mohaghegh, Shale Analytics, 2017).

In artificial intelligence-based reservoir simulation and modeling, we try to mimic or recognise the pattern in the data. Instead of using physics in its first principle and explicit form, we use physics (our scientific understanding of the fluid flow through porous media) as inspiration for building a library of clever observations. In the case of AI-Based Reservoir Models, this library of clever observations is called a customized spatio-temporal database. The spatio-temporal database is used to developing (train) a predictive model by modifying the free parameters that represent the strength of interconnections between parameters. As the training process continues, the algorithm converges to a state where it can mimic the behavior of the hydrocarbon reservoir. In other words, instead of explicitly formulating the physics, we try to deduce the physics from the observations in an implicit fashion. 
Artificial intelligence-based reservoir modelling is a young technology and it has been around for only a few years. The potential of this technology is tremendous because reservoir models can be generated in a fraction of the time and budget of traditional models while providing most of the capabilities that the traditional numerical model can provide.

\subsubsection{Artificial Neural Network}

Artificial neural network is classified to be one of the AI technologies. It can be defined as a system of information processing that perform similar to biological nervous systems. As shown in Figure 1 the output from other neurons is multiplied by the weight of the connection and enters the neuron as input. Usually in a typical neural network has many inputs and only one output. The inputs are summed and subsequently applied to the activation function and the result is the output of the neuron. (Shahkarami, A., Mohaghegh, S. D., Gholami, V., \& Haghighat, S. A., 2014, April)

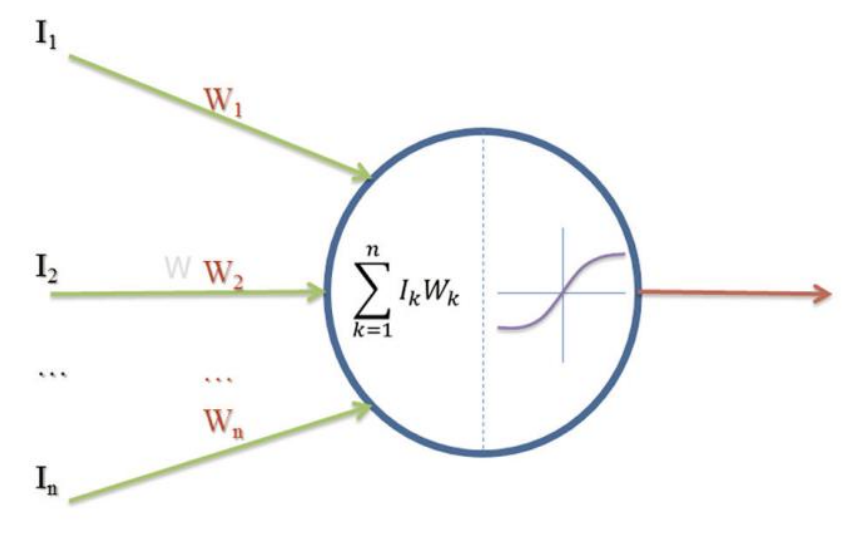

Figure 1: Schematic of Artificial Neuron

(Mohaghegh, Shale Analytics, 2017) 
An artificial neural network is a group of neurons that are arranged in particular formations. These neurons have a multilayer network structure (Figure 2). The first layer is the input layer where the number of neurons in this layer are similar to the number of attributes that are being presented to the network as input.

The second layer which is also known as a hidden layer where the neurons in this layer are responsible for modifying the data throughout the system (feature extraction). While, the last layer is the output layer where the number of neurons in this layer could be similar to the number of attributes that are being presented to the network.

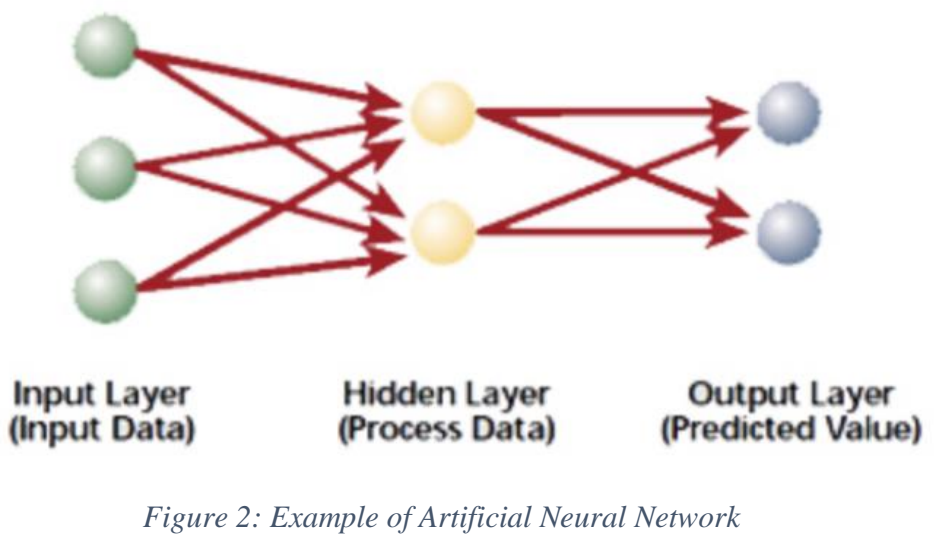

\subsection{THE SPATIO-TEMPORAL DATA BASE}

Spatio-temporal database is considered to be the backbone of the top-down reservoir model. It is intended to provide the means of integrating all the field measurements (available data) into the empirical model. In order to present the spatio-temporal database to machine learning and pattern-recognition algorithms, the shape of the database has to be flat or a matrix of rows and columns. The rows in the matrix are referenced as a record, while the columns in the matrix are referenced as attributes or parameters. The main two data types that included in spatio-temporal database are static data and dynamic data. Figure 3 shows an example of Spatio-temporal database. The data that includes in spatio-temporal database can be summerized in table 1. 


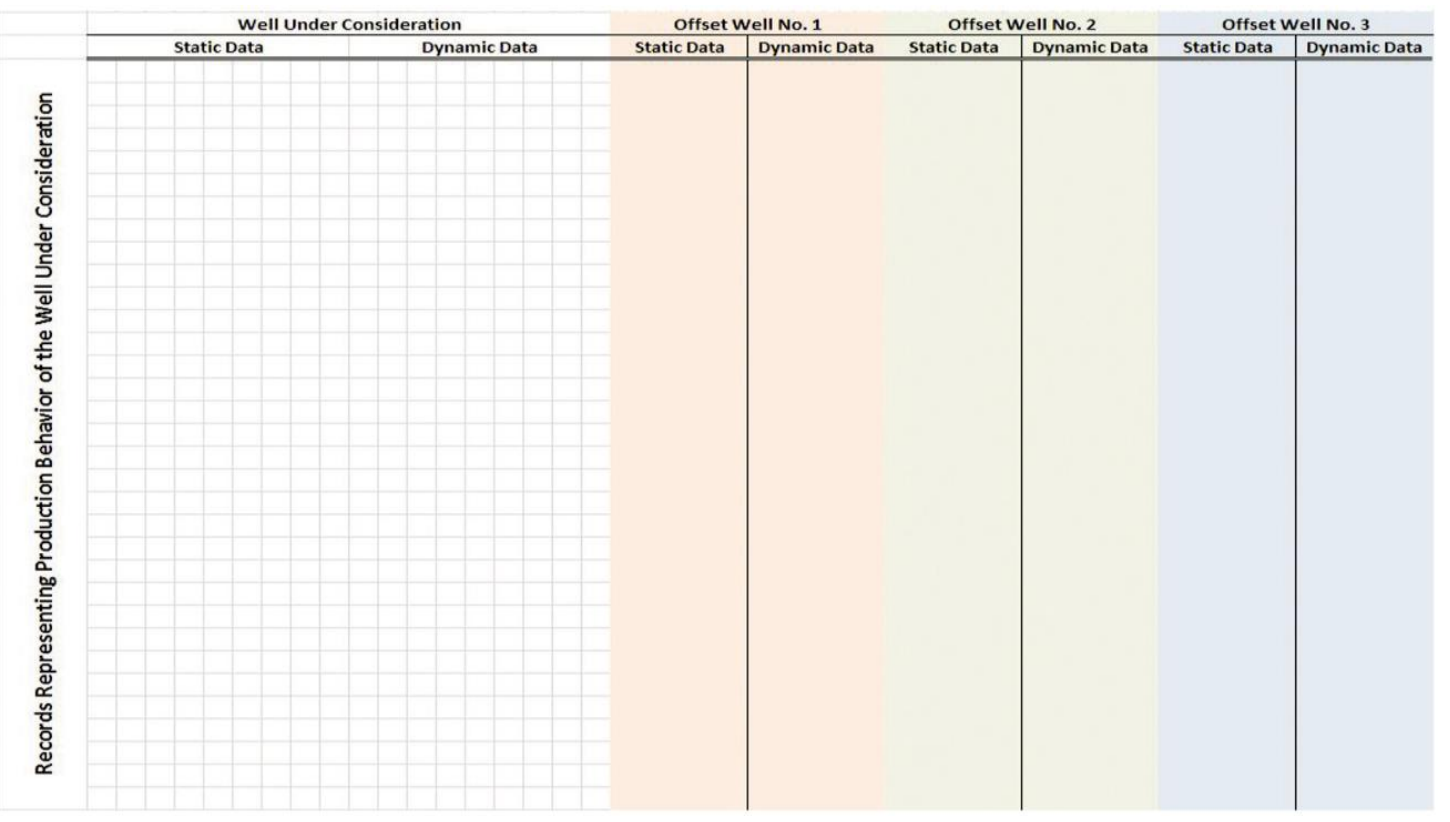

Figure 3: Example of spatio-temporal database

Table 1: Example of the data that included in the Spatio-Temporal Database

\begin{tabular}{|c|c|c|c|c|}
\hline Well Location & Well Construction & Well Completion & Formation Evaluation & Well Logs \\
\hline 1) Latitude & 1) Vertical & 1) Open Hole & 1) Formation top & 1) Gamma Ray \\
\hline 2) Longitude & 2) Horizontal & 2) Cased Hole & 2) Gross thickness & 2) Density \\
\hline 3) TVD & 3) Slanted & & 3) Porosity & 3) Resistivity \\
\hline 4) $\mathrm{MD}$ & 4) Azimuth/ & & 4) Saturation & 4) Sonic \\
\hline & Inclination & & & \\
\hline Core Analysis & Well Interventions & Production/Injection & Operational Constrains & Well Test \\
\hline 1) Permeability & 1) Workovers & 1) Oil & 1) Shut-in & 1) Reservoir \\
\hline 2) Relative & 2) Stimulation & 2) Gas & durations & Pressure \\
\hline Permeability & 3) Hydraulic & 3) Water & 2) Chock size & \\
\hline & Fracturing & & 3) WHP & \\
\hline
\end{tabular}




\subsubsection{Static Data}

Static data can be defined as the attributes that will not change with time. This data is used to build the geo- cellular model where the oil and gas reside prior production. It is known as a geological or static model. All reservoir rocks are heterogeneous and anisotropic. Static data can be divided into two separate categories. The first category is the truly static data and the second category is the dynamically-modified static data. The truly static data is the parameters that are not expected to change with time for instance the average porosity related with the drainage area (where each well is producing from) is not actually a fixed parameter. While the dynamicallymodified static data is the parameters that are expected to change with time. As new wells are drilled in the reservoir, the drainage area that is attainable to each well change with time. The average values of the static attributes that represent the drainage volume, for instance the average porosity related with the drainage area will be subject to alteration. (Mohaghegh, Data-Driven Reservoir Modeling, 2017)

\subsubsection{Dynamic Data}

Dynamic data can be defined as the attributes that can change with time. Most of the dynamic data represent human intervention in production. This intervention could be intentional or unintentional. Stimulating the well or changing the chock size are example of intentional and changes in well head pressure due to the surface facility limitations is an example of unintentional. Therefore, it is very important to let the top-down model to learn about the differences between the human intervention and reservoir behavior. These differences need to be communicated to the top-down model and the only way to communicate such information is through data. TDM will only be able to differentiate between the two sets of characteristics, and de-convolve the related signals, by learning through historical data, that there is a difference between signals coming from the reservoir and those that have been impacted by the operational constraints. 


\subsection{TOP-DOWN MODEL}

Shahab Mohaghegh is one of the pioneers in applying AI in petroleum engineering. In the recent years he introduced a new technology called a Top-Down Modeling (TDM), which is considered to be the first comprehensive data-driven reservoir modeling developed by him. TopDown Modeling (TDM) is a pioneering technology that integrates a large number of disciplines such as reservoir modeling, reservoir engineering, advanced data-driven and statistical analysis using machine learning and artificial intelligence. TDM was developed as an alternative to the traditional numerical reservoir simulation in order to build a comprehensive, cohesive and full field reservoir model. (Mohaghegh, S. D., Al-Mehairi, Y., Gaskari, R., Maysami, M., \& Khazaeni, Y., October, 2014). The distinguishing features of this technology that recognizes it from the traditional reservoir simulation are as follow;

It does not assume that we have all the information necessary to build a fully representative geological model of the asset, understanding all the underlying geological behaviour.

$>$ It does not assume that we fully understand and are able to formulate (using physics) all the complexities and intricacies (nuances) of fluid flow through porous media for the asset being modeled.

\subsubsection{Top-Down Model - Case Studies}

Several papers have been published in recent years that present the applicability datadriven reservoir modeling (Gomez, Y., Khazaeni, Y., Mohaghegh, S. D., \& Gaskari, R., 2009, January), also known as Top-Down Modeling (TDM) in developing reservoir simulation models for many different types of reservoirs.

\subsubsection{TDM for Niobrara Field}

TDM was built for a field in Weld County, Colorado, producing from Niobrara (Shahab D. Mohaghegh, S. Alireza Haghighat, Vida Gholami \& David Moreno,, April 2014). The Data was collected from more than 145 wells in order to develop a TDM for this field and perform data driven analysis. 
This data included production history, well logs, well design attributes, and dynamic production constrains. The workflow for this study included generating a geological model and reservoir delineation followed by Key Performance Indicator (KPI) analysis, and finally history matching the production data from each well and production forecasting. Figure 4 shows the list of inputs (data) for development TDM for Niobrara field.

\begin{tabular}{|c|c|c|}
\hline \multicolumn{2}{|c|}{ Top-Down Model Inputs } \\
\hline Static Data(reservoir properties) & Static Data(well design parameters) & Dynamic Data \\
\hline Pay Thickness & Well Location & Time \\
\hline Porosity & Well Drainage Area & No. of Days of Production \\
\hline Water Saturation & TVD & q-Oil (t-1) \\
\hline Porosity (offset well) & Perforation Thickness $(\mathrm{t}-2)$ \\
\hline Neutron Porosity (log) & Volume of Total Injected Fluid & Stimulation Date \\
\hline Formation Top & Weight of Injected Proppant & \\
\hline & Distance to Offset Well & \\
\hline
\end{tabular}

Figure 4: List of inputs (data) for development TDM for Niobrara field

Once the comprehensive data set is generated, Key Performance Indicator (KPI) analysis was made to define the degree of influence of each static or dynamic parameter on the production. Figure 5 demonstrates the KPI analysis result for Niobrara field.

\begin{tabular}{|c|c|c|}
\hline Rank & Feature & \% Degree of Influence \\
\hline 1 & \multirow{2}{*}{$\begin{array}{c}\text { Stimulation date } \\
\mathrm{q}(\mathrm{t}-1)-0 i l\end{array}$} & 100 \\
\hline 2 & & 93 \\
\hline 3 & $q(t-2)-0 i l$ & 79 \\
\hline 4 & Perf Thickness & 60 \\
\hline 5 & Weigth of Inj Propant & 55 \\
\hline 6 & Porosity [\%](1P] & 49 \\
\hline 7 & $X /$ Longitude & 48 \\
\hline 8 & Porh(1-sw) $[1 \mathrm{P})$ & 46 \\
\hline 9 & Porh(1-sw)-Ave.(1P) & 46 \\
\hline 10 & Water Saturation [\%] & 46 \\
\hline 11 & Elevation & 42 \\
\hline 12 & Vol of Total Inj Fluid & 42 \\
\hline 13 & Porh(1-sw)-Ave. & 40 \\
\hline 14 & Time & 40 \\
\hline 15 & Resistivity & 38 \\
\hline 16 & Porosity [\%] & 37 \\
\hline 17 & Porosity (\%)-Ave. & 37 \\
\hline 18 & Top [ft] & 37 \\
\hline 19 & Distance[1P] & 36 \\
\hline 20 & Days of Production[t] & 33 \\
\hline 21 & Top $(\mathrm{ft})(1 \mathrm{P})$ & 33 \\
\hline 22 & Y/Latitude & 32 \\
\hline
\end{tabular}

Figure 5: KPI analysis result 
Once the KPI analysis was performed, the development of TDM using the production data from 145 wells that started in 1986 and continued to December 2012 were used in neural network training. Figure 6 illustrates a good history match results for the entire field and individual wells. Also, the future productions of the wells were predicted for three years starting from year 2013.

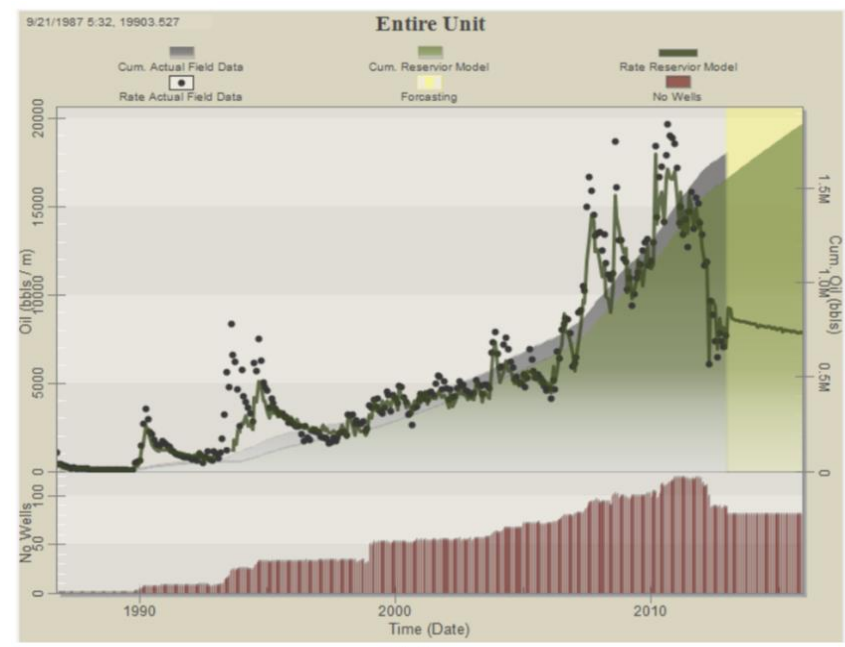

(a)

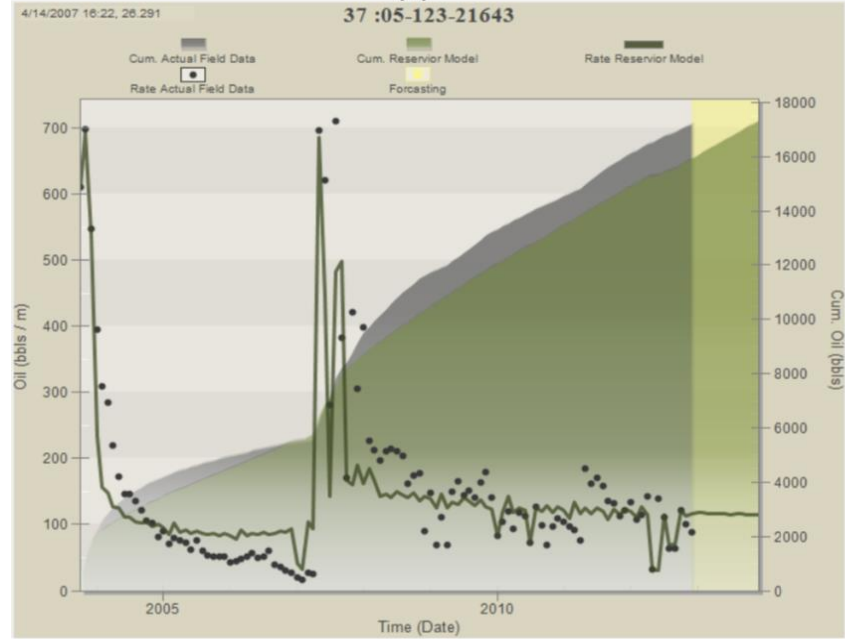

(c)

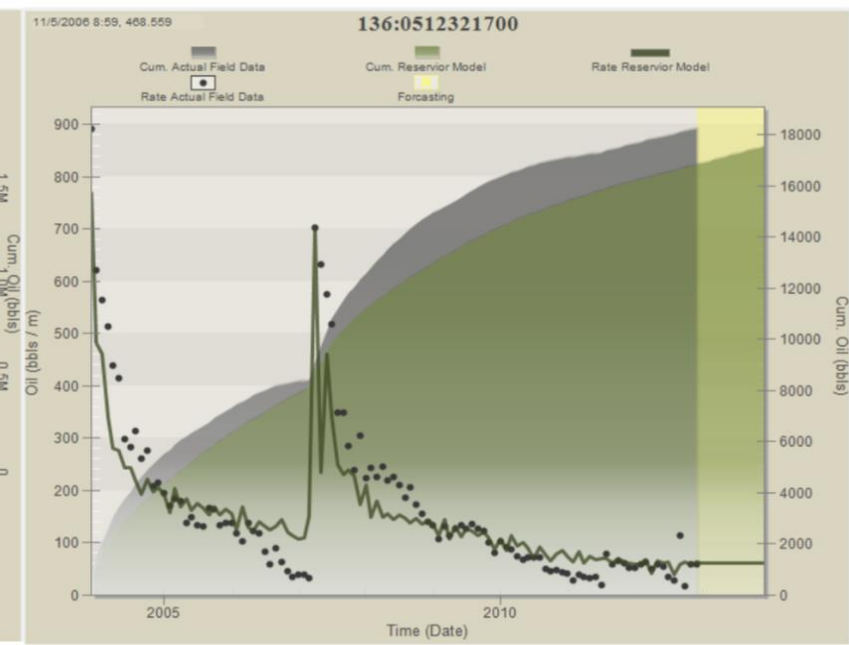

(b)

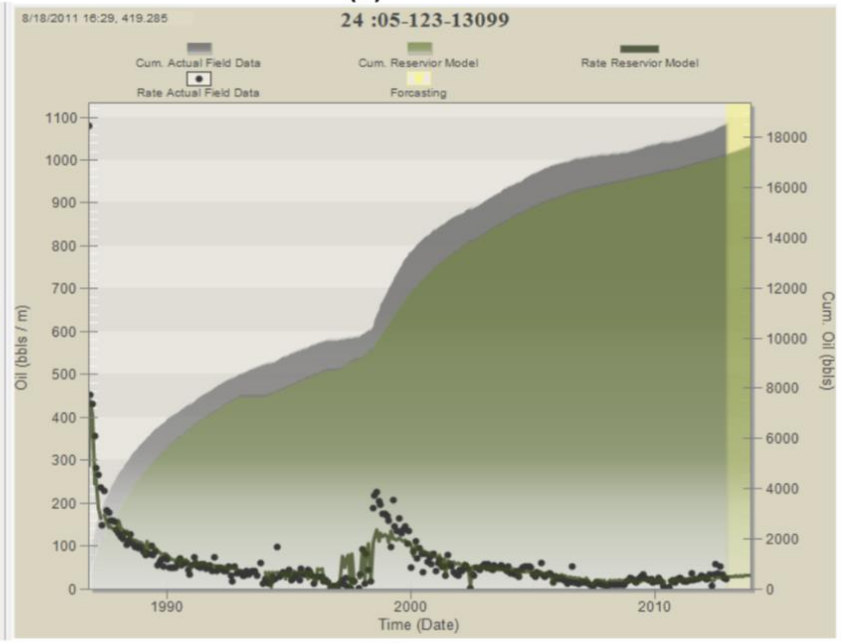

(d)

Figure 6: TDM estimations for production history and three years prediction from 2013 for $(a)$ Entire filed (b, $c, d)$ Different wells 


\subsubsection{TDM for Powder River Basin}

This study was performed on Hilight Field in the Powder River Basin, Wyoming. (Maysami, M., Gaskari, R., \& Mohaghegh, S. D. , 2013, September) The production data was collected from 185 wells started from June 1969 and extended until April 2012. Figure 7 shows the available data that were used in this analysis are well coordinates, top depth, pay thickness, porosity and completion data. However, the only dynamic data that is available beside the production history is dates and types of workovers on individual wells. Figure 8 and 9 illustrate a good history match results for the entire field and individual wells, respectively. Also, the future productions of the wells were predicted from 2013 through 2017. Gray dots and shades represent annual production history and actual cumulative production in Hilight field, respectively. The green line represents the matching result obtained from TDM model developed.

\begin{tabular}{|l|l|}
\hline \multicolumn{2}{|c|}{ Top-Down Model Inputs } \\
\hline \multicolumn{1}{|c|}{ Static Data } & \multicolumn{1}{c|}{ Dynamic Data } \\
\hline Location $-\mathrm{X}$ & Q-Oil $(\mathrm{t}-1)$ \\
\hline Location $-\mathrm{Y}$ & Q-Gas $(\mathrm{t}-1)$ \\
\hline $\begin{array}{l}\text { Depth } \\
\text { Pay Thickness }\end{array}$ & Workover $(\mathrm{t}-1)$ Date \\
\hline Completion & Workover $(\mathrm{t}-1)$ Type \\
\hline Porosity & \\
\hline
\end{tabular}

Figure 7: List of inputs (data) for development TDM for Powder River Basin 


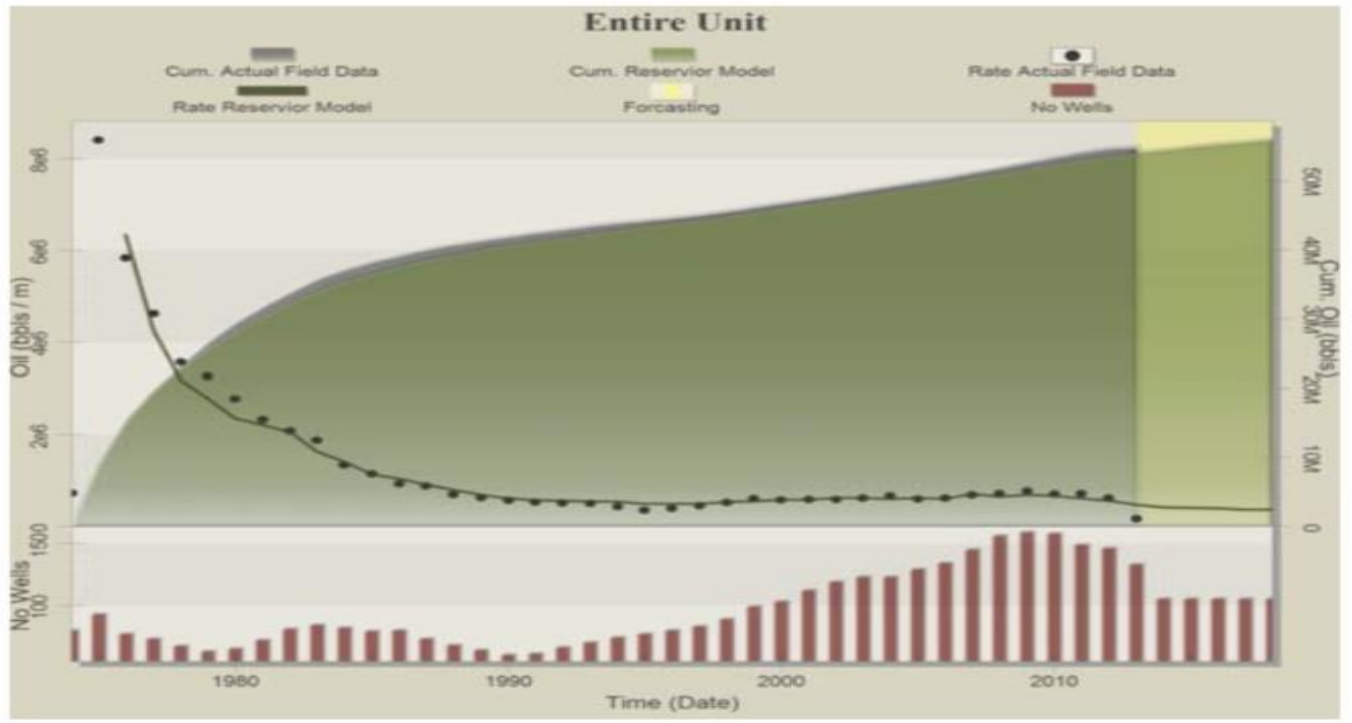

Figure 8: TDM estimations for production history and four years prediction from 2013 for the entire field

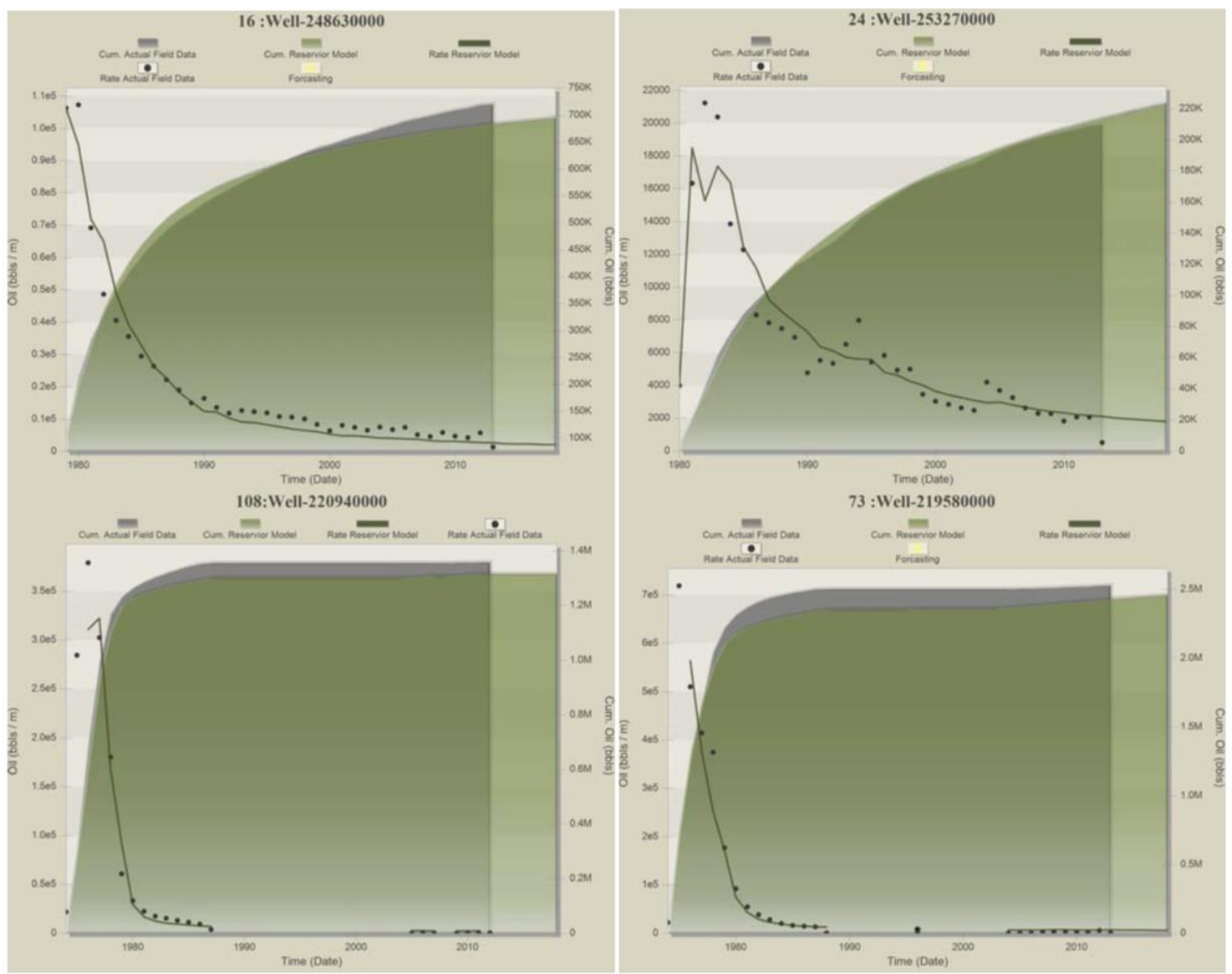

Figure 9: TDM estimations for production history and four years prediction from 2013 for different wells 


\title{
CHAPTER III
}

\author{
METHODOLOGY
}

\subsection{Introduction}

In order to accomplish the objectives of this thesis, IMagine software was used for the development of the Top-Down Model using synthetic data. The research strategy for developing the TDM is briefly explained in this chapter. The numerical reservoir simulation model that will be used to generate the data (synthetic data) from has 53 producers and 20 injectors. In addition, it has six reservoir layers. The production started in January 1995 and continued to December 2016. The production timeline consists of seven phases and each phase started at different time and can be illustrated in Figure 10. Furthermore, water injection data was available from 1995 to 2016 and the timeline can be shown in Figure 11.

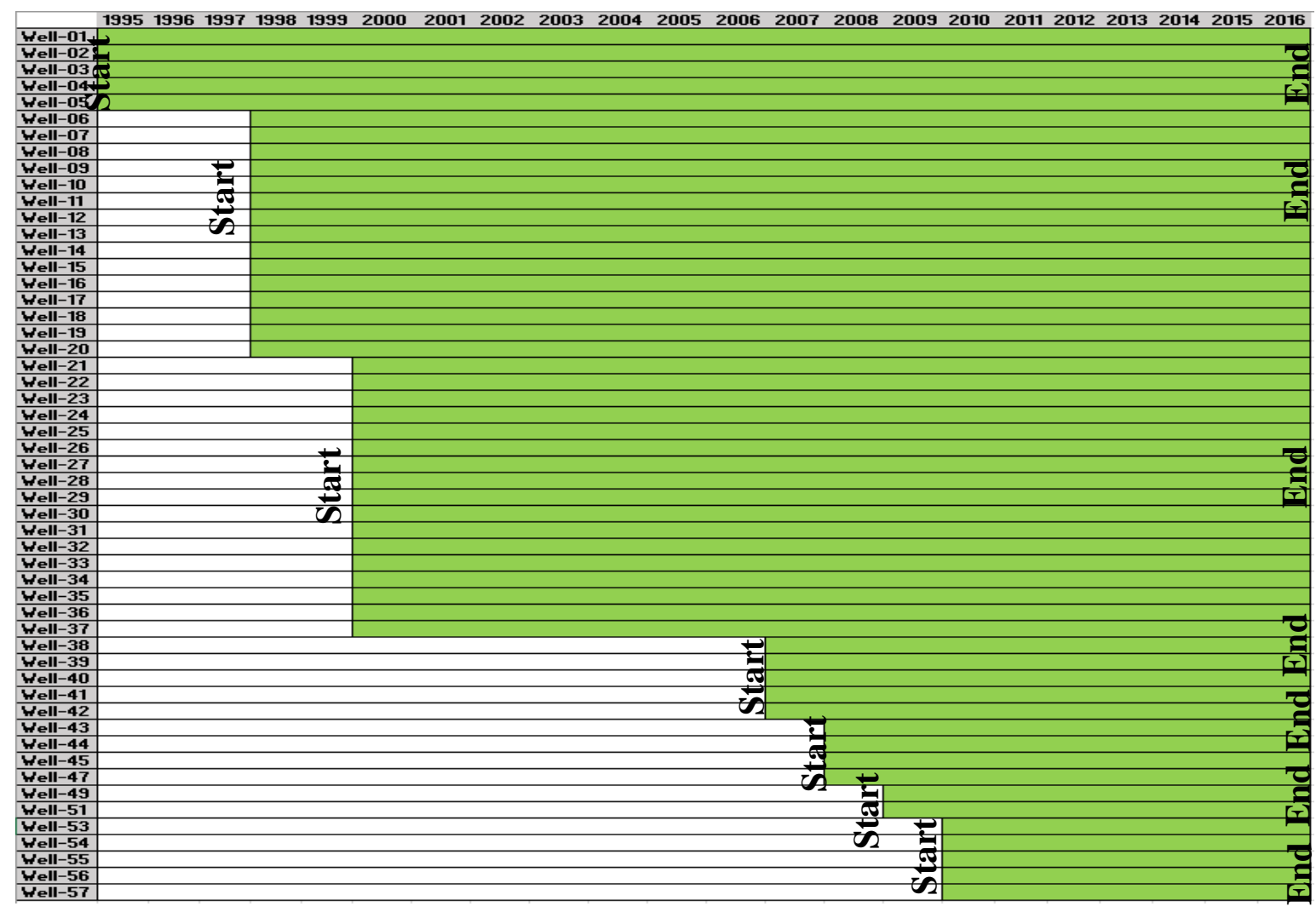

Figure 10: Production Timeline 


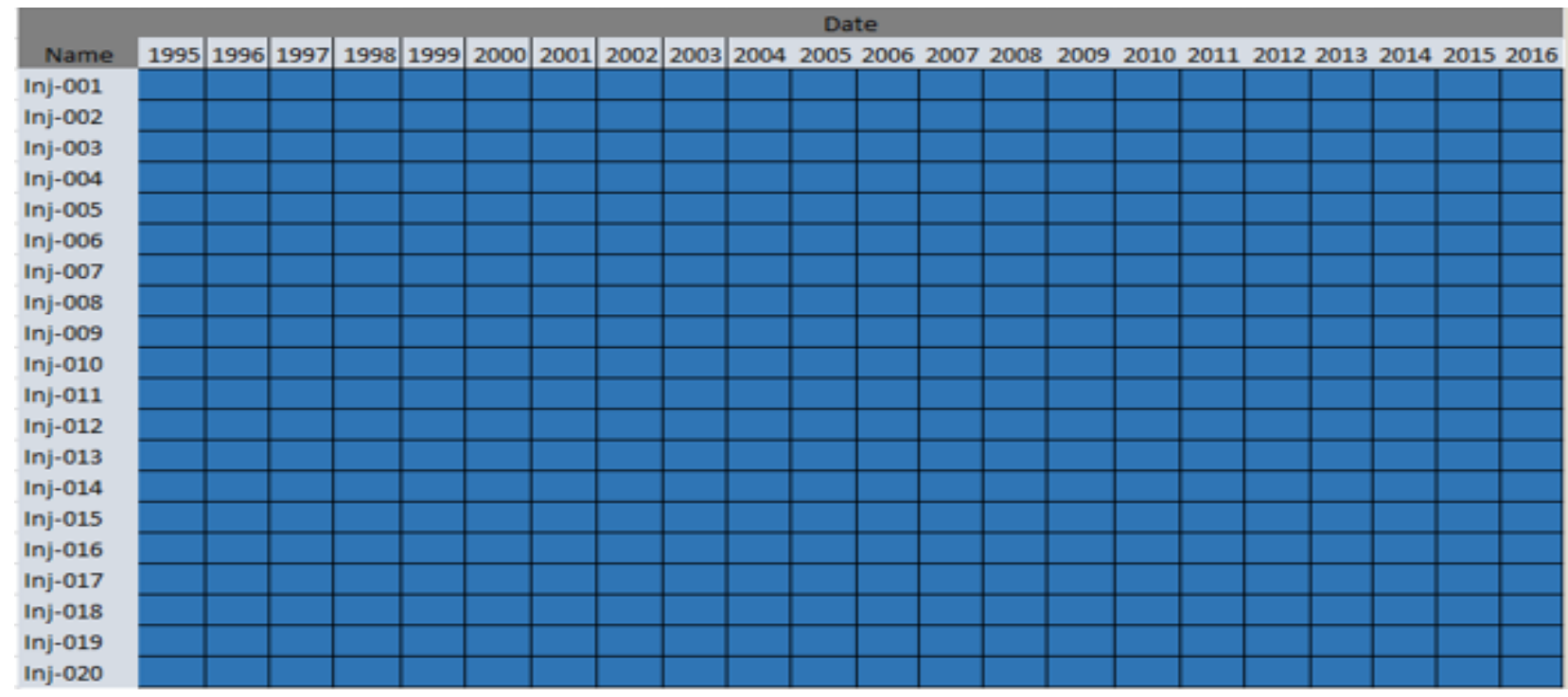

Figure 11: Water Injection Timeline

\subsection{IMagine Software}

IMagine is the only software that provides a comprehensive workflow for the development of Top-Down Models (Figure 12). It uses innovative and proprietary algorithms and technologies based on artificial neural networks, genetic optimization and fuzzy logic in order to accomplish its objective. IMagine will be used in this project in order to meet the objectives of the thesis.
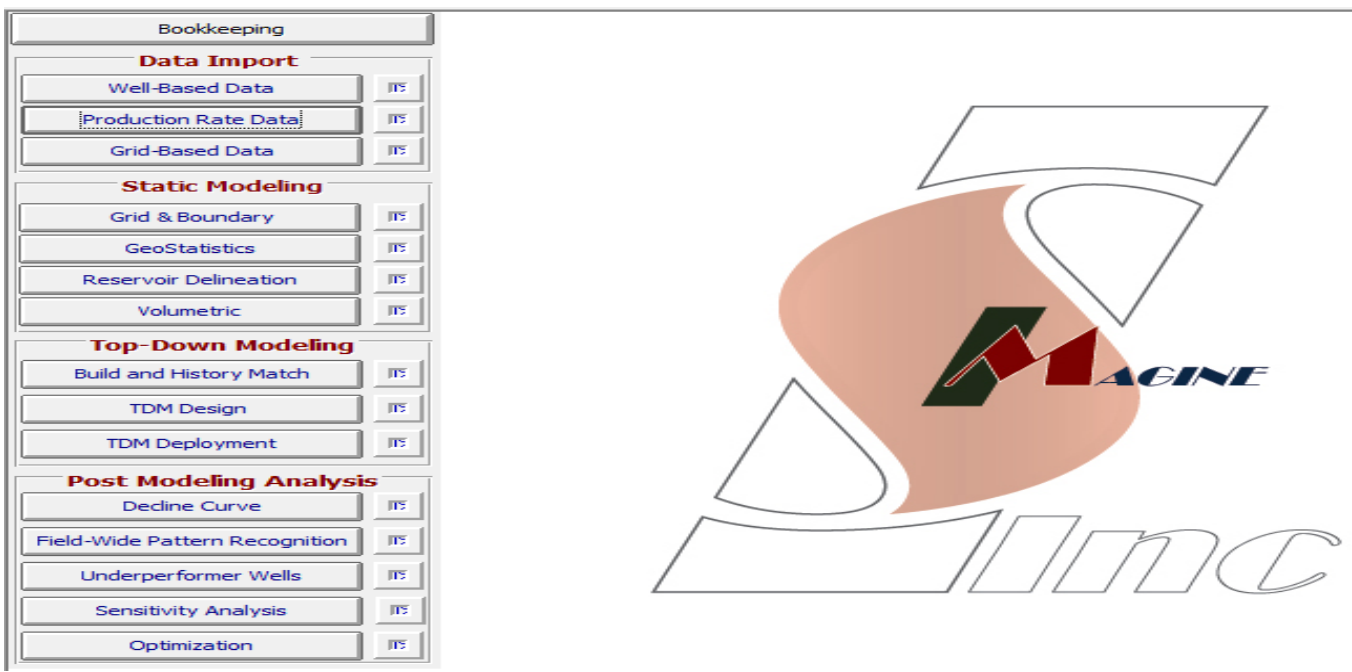

Figure 12: IMagine Software 


\subsection{Research Strategy}

The following steps were implemented in order to develop a Top-Down Model.

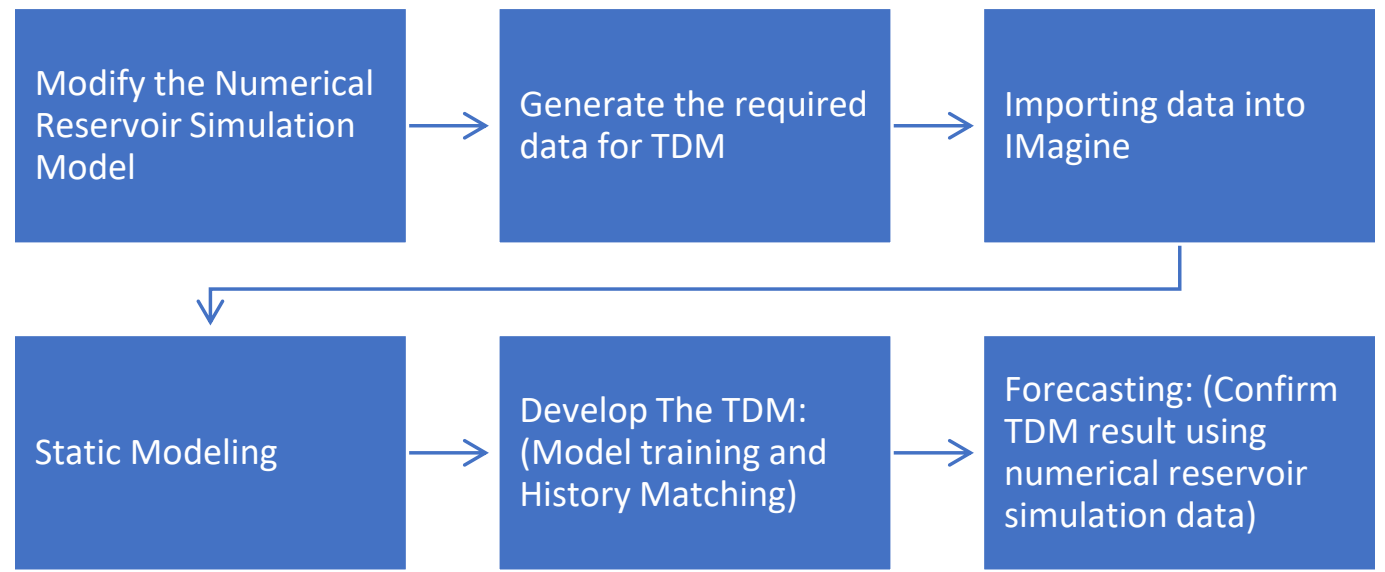

Figure 13: Research Strategy

\section{Modify the Numerical Reservoir Simulation Model}

A student at West Virginia University built the numerical reservoir simulation model and the integrity of this model was tested. Then, some modifications were made into the numerical reservoir simulation model. Therefore, the permeability and porosity of layer three and layer five were changed to be zero as shown in Figure 15 and Figure 16 respectively. Also new operational constrains were added to the model, so

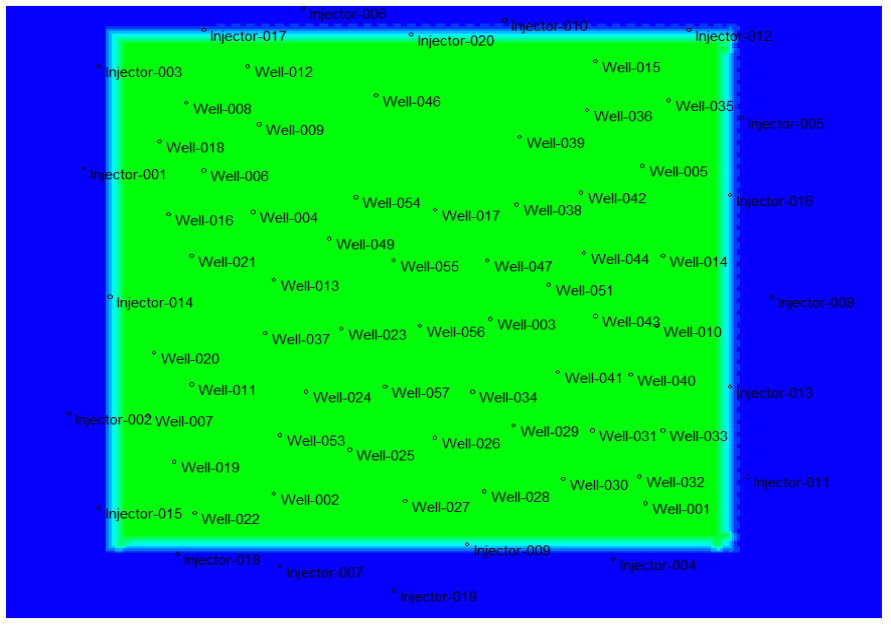

Figure 14: Well Location most of the wells were shut-in for several days and months in order to make the model more realistic. After that, the model was run using CMG software and no errors were found. As mentioned earlier the numerical reservoir simulation model includes 53 producers and 20 injectors. The location of each producer and injector can be illustrated in Figure 14. 

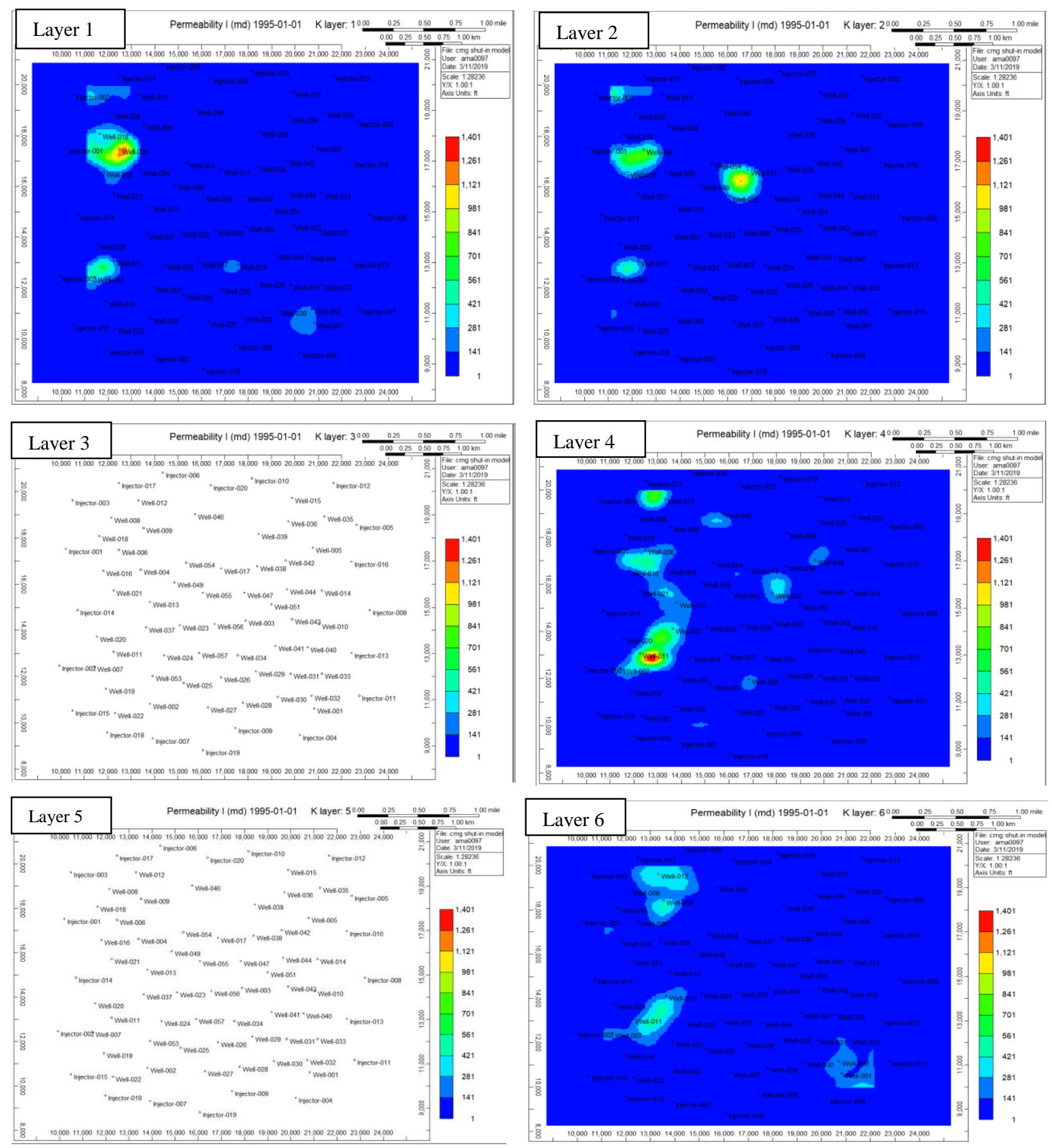

Figure 15: Permeability for the six layers 

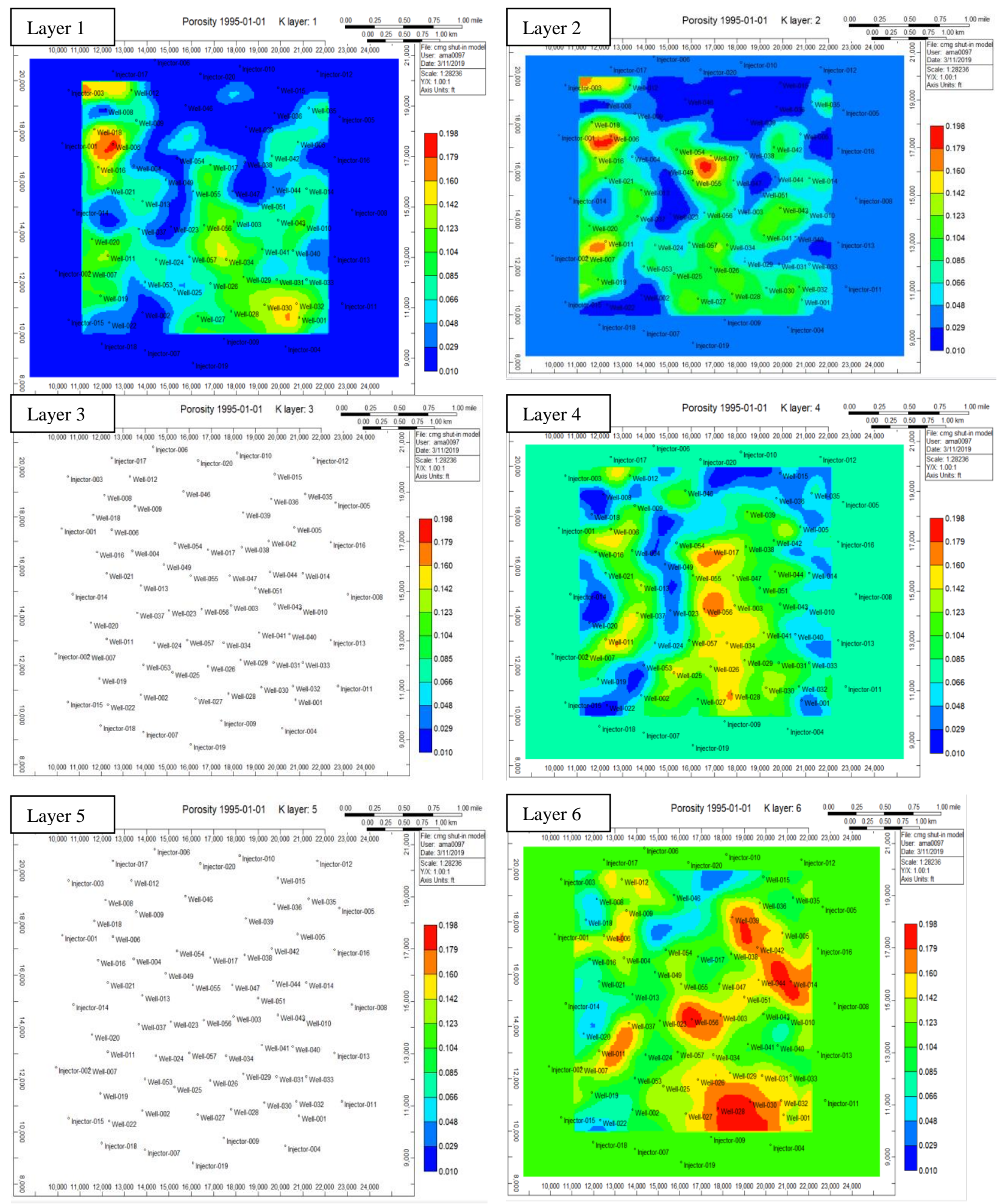

Figure 16: Porosity for the six layers 


\section{Generate the required data for the Top-Down-Model}

After running the numerical reservoir simulation model, only the required data for TDM were exported. The synthetic data was generated (exported) as a layer-based from January1995 to December 2016. Therefore, upscaling method (Figure 17) was used for all the static and dynamic attributes. Then the upscaled data (well-based data) was used for developing the TDM in order to confirm its capabilities in forecasting existing well behavior. The data generated is classified into static data and dynamic data. The static data contains of well location, well type, grid top, true-vertical-depth, average initial water saturation, average permeability, total thickness and total completion (Figure 18). While the dynamic data includes the well production data (Oil, Gas and Water) average flowing bottom hole pressure, average reservoir pressure, average water saturation and average oil saturation for 53 producers in a monthly basis from 1/31/1995 to 31/12/2016 and can be seen in Figure 19. It also includes the days of production as shown in figure 20.

\begin{tabular}{|c|c|c|}
\hline \multirow{11}{*}{ 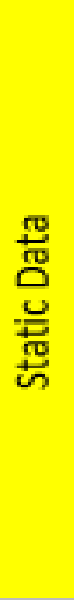 } & Well Name & Upscaling Method \\
\hline & well type & $\mathrm{N} / \mathrm{A}$ \\
\hline & X-Loc & N/A \\
\hline & Y-LOC & N/A \\
\hline & Top & N/A \\
\hline & TVD & N/A \\
\hline & Initail Sw & Average \\
\hline & $\mathrm{h}$ & Summation \\
\hline & $\mathrm{k}$ & Average \\
\hline & Porosity & Average \\
\hline & Completion & Summation \\
\hline \multirow{8}{*}{ 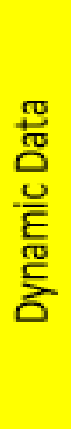 } & Oil Production & Summation \\
\hline & Gas Production & Summation \\
\hline & Water Production & Summation \\
\hline & FBHP & Average \\
\hline & Reservoir Pressure & Average \\
\hline & Water Saturation & Average \\
\hline & Oil Saturation & Average \\
\hline & Days of Production & Summation \\
\hline
\end{tabular}

Figure 17: Upscaling method 


\begin{tabular}{|c|c|c|c|c|c|c|c|c|c|c|}
\hline Well Hane & ell Type & X-Loc & Y-Loc & Top & TYD & Arerage swi & Total 1 & Arerage $\mathrm{E}$ & Arerage Por & Total Coep \\
\hline $4+11-401$ & $P$ & $20 \$ 24.25$ & 10610.57 & 4123.43 & 4329.741211 & 0.066666667 & 206.31 & 58.58 & $0.06 \$ 333333$ & 155.35 \\
\hline $4+11-402$ & $\mathrm{~F}$ & $13 \$ 12.5$ & $10 \$ 10.77$ & 4023.63 & 4301.978516 & 0.066666667 & $27 \% .35$ & 1.375 & 0.031666667 & 209.45 \\
\hline $4+11-403$ & $\mathbf{F}$ & 17901 & 14414.38 & 3919.56 & 4270.762645 & 0.066666667 & 351.2 & 13.45666667 & $0.07 \$ 333333$ & 243.64 \\
\hline $1+11-404$ & $\mathbf{F}$ & 13425.75 & 16616.57 & 4148.46 & $4418.84423 \&$ & 0.066666667 & 270.4 & 24.55333333 & 0.055 & 197.87 \\
\hline $4+11-445$ & $\mathbf{P}$ & 20774 & 17567.53 & 4045.8 & 4255.735352 & 0.066666667 & 159.93 & 12.76 & $0.05 \$ 333333$ & 127.35 \\
\hline 11+11-446 & $\mathbf{F}$ & $124 \$ 6.5$ & 17467.43 & 4209.49 & 4412.863281 & 0.066666667 & 203.38 & 315.235 & 0.098333333 & 147.81 \\
\hline $4+11-4 * 7$ & $\mathbf{F}$ & 11436.75 & 12412.38 & 4165.89 & 4521.438965 & 0.066666667 & 355.54 & 158.3916667 & $0.0 \leqslant 5$ & 244.85 \\
\hline $4+11-40 *$ & $\mathbf{F}$ & 12155 & $1 \$ 868.83$ & 4271.89 & 4346.865723 & 0.066666667 & 74.97 & $5.31 \$ 333333$ & 0.021666667 & 61.69 \\
\hline 14+11-4*4 & $\mathbf{P}$ & 13536.25 & 18418.38 & 4229.81 & 4347.341747 & 0.066666667 & 117.52 & 65.31166667 & 0.06 & 92.44 \\
\hline 4.11-414 & $\mathbf{P}$ & 21050.25 & 14264.23 & 4098.36 & 4305.600098 & 0.066666667 & 207.24 & $20.55 \$ 33333$ & 0.06 & 160.3 \\
\hline ㄴ.11-411 & $\mathbf{P}$ & 12265.5 & 13063.02 & 4147.67 & 4525.955566 & 0.066666667 & 378.29 & 177.98 & $0.08 \$ 333333$ & 262.53 \\
\hline $4-11-412$ & $\mathbf{F}$ & 13315.25 & 19619.58 & 4286.31 & 4346.079102 & 0.073333333 & 54.78 & 132.0183333 & $0.07 \$ 333333$ & 50.65 \\
\hline $4+11-413$ & $\mathbf{P}$ & $13 \& 12.5$ & 15215.17 & 4109.26 & 4457.023438 & 0.066666667 & 347.77 & 50.99833333 & 0.066666667 & 245.05 \\
\hline $4+11-114$ & $\mathrm{~F}$ & 21160.75 & 15715.68 & 4053.9 & 4267.547852 & 0.066666667 & 213.65 & $17.21 \$ 33333$ & 0.066666667 & 156.79 \\
\hline $4+11-415$ & $\mathbf{F}$ & 19890 & 19719.68 & $415 \& .46$ & 4320.705566 & 0.066666667 & 162.24 & 2.823333333 & 0.026666667 & 131.53 \\
\hline $4+11-416$ & $\mathbf{F}$ & $11 \$ 23.5$ & 16566.52 & 4196.34 & 4454.918445 & 0.066666667 & $25 \% .5 \%$ & $103.67 \$ 3333$ & 0.075 & 184.84 \\
\hline 4.11-417 & $\mathbf{F}$ & $16 \$ 51.25$ & 16666.63 & 4004.33 & $4294.4 \$ 877$ & 0.066666667 & 290.14 & 91.59166667 & 0.08 & 207.55 \\
\hline 4.11-41* & $\mathbf{P}$ & 11657.75 & 18068.03 & 4242.67 & 4382.793945 & 0.066666667 & 140.14 & 80.735 & 0.06 & 105.8 \\
\hline W.11-419 & $\mathrm{P}$ & 11934 & 11461.43 & 4118.63 & $4450.8256 \& 4$ & 0.066666667 & 332.19 & 20.465 & 0.066666667 & 235.65 \\
\hline $4+11-42 \bullet$ & $\mathbf{F}$ & 11547.25 & 13713.68 & 4194.25 & $45 \$ 8.25243$ & 0.366666667 & 394 & 6.253333333 & 0.046666667 & 266.47 \\
\hline $4+11-\bullet 21$ & $\mathbf{P}$ & 12265.5 & 15715.68 & 4178.06 & 4520.924805 & 0.066666667 & 342.87 & 21.72166667 & 0.056666667 & 238.45 \\
\hline $4+11-422$ & $\mathbf{P}$ & 12320.75 & 10410.38 & 4072.71 & 4358.009766 & 0.073333333 & $2 \$ 5.31$ & 0.891666667 & 0.021666667 & 213.33 \\
\hline $4+11-423$ & $\mathbf{F}$ & $150 \$ 3.25$ & $14214.1 \%$ & $4054.5 \&$ & 4350.875488 & 0.066666667 & 291.31 & 3.406666667 & 0.03 & 218.48 \\
\hline $14+11-424$ & $\mathbf{P}$ & 14420.25 & 12912.88 & 4076.38 & $43 \& 3.918445$ & 0.066666667 & 307.54 & 8.456666667 & 0.053333333 & 227.48 \\
\hline 14-11-425 & $\mathbf{F}$ & 15249 & 11711.68 & 3978.7 & 4313.311523 & 0.066666667 & 334.61 & 10.905 & 0.066666667 & 240.72 \\
\hline $4+11-426$ & $\mathrm{~F}$ & $16 \$ 51.25$ & 11961.93 & 3898.57 & $4275.4 \$ 0957$ & 0.066666667 & 376.92 & 41.46 & 0.073333333 & 257.08 \\
\hline 닌-117 & $\mathbf{P}$ & 16298.75 & 10660.63 & 3900.99 & 4272.945313 & 0.066666667 & 371.96 & 22.42333333 & 0.071666667 & 247.76 \\
\hline $4+11-42 *$ & $\mathbf{P}$ & 17790.5 & $10 \$ 60 . \$ 3$ & 3946.28 & $4269.3837 \$ 9$ & 0.066666667 & 323.1 & 25.46333333 & 0.091666667 & 228.82 \\
\hline $4+11-424$ & $\mathbf{P}$ & $1 \$ 343$ & $12212.1 \%$ & 3969.65 & 4273.86084 & 0.066666667 & 304.22 & 9.071666667 & 0.071666667 & 218.84 \\
\hline $4+11-4$ & $\mathbf{F}$ & $192 \$ 2.25$ & 11111.07 & 4008.02 & 4290.356934 & 0.066666667 & 282.33 & 31.49166667 & $0.0 \$ \$ 333333$ & 215.94 \\
\hline $4+11-431$ & $\mathbf{P}$ & $19 \$ 34.75$ & 12112.07 & 4052.84 & 4303.44043 & 0.066666667 & 250.55 & 18.02166667 & 0.063333333 & 192.26 \\
\hline $4+11-432$ & $\mathbf{F}$ & 20718.75 & 11161.12 & 4118.89 & 4337.911133 & 0.066666667 & 219.01 & 67.23166667 & $0.0 \$ 3333333$ & 164.07 \\
\hline $4+11-433$ & $\mathbf{F}$ & 21160.75 & 12112.07 & 4152.26 & $4337.445 \% 01$ & 0.066666667 & $1 \$ 5.1 \&$ & 25.63666667 & 0.055 & 138.58 \\
\hline $4+11-434$ & $\mathbf{P}$ & 17569.5 & 12912.88 & 3919.78 & 4269.735352 & 0.066666667 & 349.97 & 40.48 & 0.09 & 242.3 \\
\hline $4.11-435$ & $\mathbf{F}$ & 21271.25 & 18918.88 & 4135.81 & $4288.61 \$ 164$ & 0.066666667 & $152 . \$ 1$ & 3.735 & 0.046666667 & $127 . \$ 2$ \\
\hline $4.11-436$ & $\mathbf{F}$ & 19724.25 & 18718.68 & 4100.81 & 4257.620606 & 0.066666667 & 156.82 & 4.941666667 & 0.035 & 128.43 \\
\hline $4+11-437$ & $\mathbf{F}$ & 13646.75 & 14114.08 & 4120.53 & 4480.970703 & 0.066666667 & 360.46 & 110.14 & 0.076666667 & 253.22 \\
\hline $4+11-43 *$ & $\mathbf{F}$ & 18348.25 & 16766.73 & 3965.57 & 4277.134766 & 0.066666667 & 311.58 & 8.975 & 0.053333333 & 218.77 \\
\hline $4+11-43$ & $\mathbf{P}$ & $1 \& 453.5$ & 18168.13 & 4062.66 & 4258.981445 & 0.066666667 & 196.32 & 12.18 & 0.05 & 148.65 \\
\hline $4+11-44$ & $\mathbf{F}$ & 20553 & 13263.22 & 4108.25 & 4328.149902 & 0.066666667 & 219.91 & 9.266666667 & 0.046666667 & 165.8 \\
\hline $4+11-441$ & P & 19171.75 & 13313.28 & 4024.76 & $42 \$ 1.693 \$ 48$ & 0.066666667 & 256.92 & 14.493333333 & 0.073333333 & 194.36 \\
\hline $1+11-442$ & $\mathbf{F}$ & 19613.75 & 17016.98 & 4044.97 & 4267.566845 & 0.066666667 & 222.61 & $46.0 \$ \$ 33333$ & 0.071666667 & 169.15 \\
\hline $4+11-443$ & $\mathbf{P}$ & 19890 & 14464.42 & 4039.05 & 4294.96582 & 0.066666667 & 255.92 & 11.05 & $0.06 \& 333333$ & 196.18 \\
\hline $4=11-44$ & $\mathbf{P}$ & 19669 & 15765.73 & 3984.66 & 4277.643066 & 0.066666667 & 292.99 & 9.205 & 0.056666667 & 211.55 \\
\hline $1+11-446$ & $\mathbf{F}$ & 15746.25 & 19018.98 & 4189.91 & 4338.42627 & 0.066666667 & $14 \$ .52$ & 31.91333333 & 0.036666667 & 114.29 \\
\hline $14+11-447$ & $\mathbf{P}$ & $17 \$ 45.75$ & 15615.58 & 3913.5 & 4277.880371 & 0.066666667 & 364.4 & 51.42666667 & 0.06 & 250.41 \\
\hline $4+11-445$ & $\mathbf{P}$ & $14 \$ 62.25$ & 16066.03 & 4089.14 & 4373.851563 & 0.066666667 & 284.72 & 3.845 & 0.036666667 & 211.77 \\
\hline $4+11-451$ & $\mathbf{P}$ & 19006 & 15115.07 & 3952.62 & 4273.938965 & 0.066666667 & 321.3 & $5.0 \leqslant 5$ & 0.053333333 & 228.46 \\
\hline $4+11-453$ & $\mathbf{P}$ & 13923 & 12011.98 & 4077.76 & 4380.805176 & 0.066666667 & 303.05 & 4.286666667 & 0.046666667 & 224.91 \\
\hline $4-11-454$ & $\mathbf{P}$ & 15354.5 & 16916.88 & 4103.11 & 4371.564941 & 0.066666667 & 268.45 & 14.705 & 0.046666667 & 198.83 \\
\hline $4+11-455$ & $\mathbf{P}$ & 16077.75 & 15615.58 & 4008.86 & 4297.27002 & 0.066666667 & 288.42 & $43.5 \$ 333333$ & 0.068333333 & 210.8 \\
\hline $4+11-456$ & P & 16575 & 14264.23 & 3937.44 & 4288.834473 & 0.066666667 & 351.4 & 22.49333333 & $0.0 \$ 5$ & 247.86 \\
\hline $4.11-457$ & $\mathbf{P}$ & 15912 & 13012.98 & 3984.05 & 4291.50293 & 0.066666667 & 307.44 & $4.56 \$ 333333$ & 0.056666667 & 224.51 \\
\hline Imiecter-4*1 & 1 & 10221.25 & 17517.48 & 4215.07 & 4404.933106 & 0.666666667 & 189.86 & 66.66666667 & 0.043333333 & 140.47 \\
\hline Injecter-\$*Z & I & 9945 & 12462.43 & 4182.66 & 4536.637645 & 0.666666667 & 353.97 & 66.66666667 & 0.043333333 & 242.28 \\
\hline Injecter-4*3 & I & 10497.5 & 19619.58 & 4322.04 & 4360.979981 & 0.666666667 & 38.93 & 66.66666667 & 0.043333333 & 36.08 \\
\hline Injecter-404 & 1 & 20221.5 & 9459.43 & 4007.95 & 4274.199219 & 0.666666667 & 266.24 & 66.66666667 & 0.043333333 & 203.76 \\
\hline Injeter-405 & 1 & 22652.5 & 18568.53 & 4146.9 & 4311.834961 & 0.666666667 & 16.4 .94 & 66.66666667 & 0.043333333 & 133.2 \\
\hline Injecter-4*6 & 1 & 14365 & $20 \$ 20.78$ & $4258 . \$ 1$ & 4342.679688 & 0.666666667 & $\$ 3.87$ & 66.66666667 & 0.043333333 & 68.48 \\
\hline Injecter-4*7 & 1 & 13923 & 9309.27 & 3980.75 & 4272.998535 & 0.666666667 & 292.25 & 66.66666667 & 0.043333333 & 207.79 \\
\hline Injecter- & 1 & 23205 & $14 \$ 64 . \$ 3$ & 4113.57 & 4287.615723 & 0.666666667 & 174.06 & 66.66666667 & 0.043333333 & 137.69 \\
\hline Injeter-4*4 & 1 & 17454 & 9754.73 & 3911.88 & 4260.341797 & 0.366666667 & 348.47 & 66.66666667 & 0.043333333 & 235.74 \\
\hline Injecter-414 & 1 & $1 \$ 177.25$ & 20570.52 & 4198.42 & 4348.562012 & 0.666666667 & 150.13 & 66.66666667 & 0.043333333 & 115.95 \\
\hline Injecter-111 & I & 22763 & 11161.12 & 4222.29 & 4357.049316 & 0.666666667 & 134.77 & 66.66666667 & 0.043333333 & 99.25 \\
\hline Injecter-12 & 1 & 21658 & 20370.33 & 4210.39 & $4352.5214 \$ 4$ & 0.5 & 142.12 & 66.66666667 & 0.043333333 & 114.69 \\
\hline Injecter-13 & 1 & 22431.5 & 13012.98 & 4186.36 & 4343.843262 & 0.44 & 157.49 & 66.66666667 & 0.043333333 & $117 . \$ 3$ \\
\hline Injecter-14 & 1 & 10718.5 & $14 \$ 64 . \$ 3$ & 4176.88 & 4516.955078 & 0.496666667 & 340.07 & 66.66666667 & 0.043333333 & 233.74 \\
\hline Injeter-415 & 1 & 10497.5 & 10510.48 & 4122.34 & $4445 . \$ 0957$ & 0.666666667 & 323.46 & 66.66666667 & 0.043333333 & 231.02 \\
\hline Injeter-16 & 1 & 22431.5 & 16966.93 & 4109.66 & 4265.019531 & 0.44 & 155.36 & 66.66666667 & 0.043333333 & 121.98 \\
\hline I-jecter-417 & 1 & 12486.5 & 20370.33 & 4312.31 & 4359.291016 & 0.493333333 & 47 & 66.66666667 & 0.043333333 & 39.53 \\
\hline Injecter-41* & I & 11989.25 & 9554.53 & 4078.52 & 4359.869141 & 0.666666667 & 281.37 & 66.66666667 & 0.043333333 & 210.39 \\
\hline Injectur-119 & 1 & 16077.75 & $8 \$ 0 \$ .7 \$$ & 3899.72 & 4259.931152 & 0.666666667 & 360.22 & 66.66666667 & 0.043333333 & 237.7 \\
\hline Injecter- & 1 & 16.409 .25 & 20270.23 & $4217.1 \%$ & 4341.55957 & 0.366666667 & 124.39 & 66.66666667 & 0.043333333 & 95.17 \\
\hline
\end{tabular}

Figure 18: Static Data 


\begin{tabular}{|c|c|c|c|c|c|c|c|c|}
\hline Vell Name & Date (month) & Average FBHP & Yell Oil Prod. (bbls) & Vell Gas Prod. (scf) & Vell Vater Prod. (bbls) & Average Pressure & Average Sy & Average So \\
\hline Well-001 & 113111995 & 3342.351736 & 0 & 0 & 0 & 3342.351736 & 0.06652293 & 0.600143737 \\
\hline Well.001 & 212811995 & 2108.782009 & 701133.6875 & 292672096 & 0.136530116 & 2585.924805 & 0.066891817 & 0.59977485 \\
\hline Well-001 & $3 \mid 3111995$ & 2085.913488 & 679416.75 & 283606848 & 2014.054199 & 2522.946541 & 0.089479208 & 0.577187459 \\
\hline Well-001 & $4 / 3011995$ & 2136.738883 & 502774.0313 & 209871440 & 31806.01563 & 2721.115755 & 0.119262127 & 0.54740454 \\
\hline Well.001 & $5 / 3111995$ & 2118.808338 & 453759.1563 & 189411312 & 65220.92969 & 2809.369448 & 0.141206523 & 0.525460144 \\
\hline Well-001 & $6 r 3011995$ & 2083.940405 & 330480.8125 & 137951600 & 102204.5469 & 2822.27251 & 0.155329031 & 0.511337635 \\
\hline Well-001 & $7 / 31 / 1995$ & 1856.713111 & 343542.1563 & 143403760 & 145666.7969 & 2711.091687 & 0.16421502 & 0.502451647 \\
\hline Well-001 & 813111995 & 2239.092273 & 234933.9531 & 98067776 & 132748.0625 & 2896.093167 & 0.174314982 & 0.492351685 \\
\hline Well-001 & $9 / 30 / 1995$ & 2211.151847 & 222312.7344 & 92799336 & 148000.0781 & 2910.909473 & 0.17440624 & 0.492260426 \\
\hline Well-001 & $10 / 3111995$ & 2195.267015 & 217813.2344 & 90921112 & 162621.0469 & 2897.924427 & 0.179519348 & 0.487147319 \\
\hline Well-001 & 1113011995 & 1986.418441 & 230887.0781 & 96378496 & 188443.8125 & 2794.711043 & 0.183816457 & 0.48285021 \\
\hline Well-001 & $12 / 31 / 1995$ & 2029.879828 & 217258.2188 & 90689440 & 199377.9063 & 2813.889373 & 0.188697031 & 0.477969635 \\
\hline Well.001 & 113111996 & 1974.958102 & 214860.8438 & 89688704 & 215884.2031 & 2791.223759 & 0.188128522 & 0.478538144 \\
\hline Well-001 & 212911996 & 3657.741068 & 0 & 0 & 0 & 3657.741068 & 0.236278025 & 0.430388642 \\
\hline Well.001 & 313111996 & 2185.166228 & 166565.8438 & 69529072 & 233454.7031 & 2951.287456 & 0.193235816 & 0.473430851 \\
\hline Well.001 & 413011996 & 1884.743689 & 198828.3438 & 82996312 & 239446.9688 & 2755.542733 & 0.197671672 & 0.468994995 \\
\hline Well.001 & $5 / 31 / 1996$ & 2212.4585555 & 155325.5156 & 64837056 & 210828.1875 & 2912.130025 & 0.19740553 & 0.469261137 \\
\hline Well-001 & $6 / 3011996$ & 3704.622103 & 0 & 0 & 0 & 3704.622103 & 0.240907953 & 0.425758713 \\
\hline Well.001 & $7 / 3111996$ & 3852.128355 & 0 & 0 & 0 & 3852.128355 & 0.248224683 & 0.418441984 \\
\hline Well.001 & 813111996 & 2190.746826 & 133787.4531 & 55846492 & 274317.9063 & 2967.119834 & 0.203978763 & 0.462687903 \\
\hline Well.001 & $9 / 30 / 1996$ & 2121.935889 & 147326.4688 & 61498044 & 239908.8125 & 2894.833171 & 0.203733361 & 0.462933306 \\
\hline Well-001 & 1013111996 & 2101.691706 & 147404.0781 & 61530432 & 248331.4063 & 2862.859241 & 0.205521135 & 0.461145531 \\
\hline Well-001 & 1113011996 & 2174.59115 & 131375.6406 & 54839736 & 233560.2656 & 2898.254093 & 0.207806646 & 0.458860021 \\
\hline Well-001 & $12+31 / 1996$ & 2106.464253 & 139739.7344 & 58331128 & 256343.7813 & 2866.176222 & 0.208977041 & 0.457689626 \\
\hline
\end{tabular}

Figure 19: Dynamic Data

\begin{tabular}{|c|c|c|c|c|c|c|c|c|c|c|c|c|c|c|c|c|c|c|c|}
\hline Well Name & $7 / 31 / 20028 / 31$ & $/ 20029$ & 9/30/2002 & $10 / 31 / 20021$ & $11 / 30 / 2002$ & $.2 / 31 / 20021 / 3$ & $/ 31 / 20032$ & $2 / 28 / 2003 \quad 3 / 3$ & /31/2003 4/ & $4 / 30 / 20035 /$ & $5 / 31 / 20036$ & $6 / 30 / 20037 / 3$ & //31/2003 8/ & $8 / 31 / 20039 / 3$ & $9 / 30 / 200310 /$ & $0 / 31 / 2003 \quad 11 / 30$ & $1 / 30 / 2003 \quad 12 / 31$ & /2003 & $1 / 31 / 2004$ \\
\hline Well-001 & 19 & 22 & & 24 & 21 & 23 & 25 & 22 & 21 & 20 & 23 & 22 & & 21 & 20 & 26 & 19 & & 23 \\
\hline Well-002 & 23 & & & & 21 & 22 & & 16 & 26 & 22 & 22 & 24 & 28 & 24 & 24 & 27 & 21 & & 22 \\
\hline Well-003 & & 23 & 22 & 24 & 23 & 24 & 21 & 20 & 21 & 23 & & 22 & 24 & & & 22 & 23 & 28 & \\
\hline Well-004 & 24 & 26 & & 26 & 21 & 24 & 20 & 21 & & & 24 & 24 & & 23 & & 23 & 25 & 22 & 18 \\
\hline Well-005 & 18 & & 19 & 24 & 23 & 22 & 24 & 25 & 27 & 23 & 25 & 22 & 21 & 26 & 19 & & 23 & 20 & 21 \\
\hline Well-006 & 21 & 27 & 20 & & 24 & 23 & & 20 & 25 & 24 & 27 & & 25 & 22 & 22 & 27 & 25 & 22 & 20 \\
\hline Well-007 & 20 & & 25 & 22 & & 24 & 26 & 22 & 24 & 18 & 22 & & 23 & 25 & 23 & 25 & 25 & 23 & 20 \\
\hline Well-008 & 23 & 21 & & 23 & 21 & 21 & & 22 & 22 & 27 & 23 & 22 & & 26 & & 25 & 23 & 25 & 23 \\
\hline Well-009 & & 25 & 24 & 24 & 19 & 22 & 25 & & 25 & 24 & 20 & 21 & 26 & & 25 & 21 & 23 & & \\
\hline Well-010 & 26 & 22 & 20 & 24 & 24 & & 20 & 21 & 25 & 23 & 24 & 20 & 22 & 25 & 23 & 22 & 21 & 26 & 26 \\
\hline Well-011 & 23 & 29 & 20 & & 22 & 17 & 20 & 21 & & 21 & 22 & 22 & 25 & 27 & 23 & & & 24 & \\
\hline Well-012 & 23 & & 20 & 21 & 22 & 22 & 24 & 20 & 24 & 24 & 21 & & 19 & & & 24 & & & 25 \\
\hline Well-013 & 19 & 22 & 24 & 26 & 18 & 22 & & 24 & 26 & 24 & 24 & 28 & 19 & 27 & & & & & 29 \\
\hline Well-014 & 26 & & 21 & 22 & & 26 & & 24 & 25 & 24 & 22 & 21 & 24 & 20 & 24 & 20 & 19 & 19 & 25 \\
\hline Well-015 & & & 25 & 21 & & 26 & 26 & 21 & 27 & 25 & 22 & 23 & 22 & & & 24 & & 21 & 24 \\
\hline Well-016 & 18 & 24 & 23 & 27 & 19 & 23 & & 19 & 23 & & 26 & 18 & 22 & 21 & 27 & & & & 26 \\
\hline Well-017 & 24 & & & 21 & 22 & 23 & 25 & 20 & 21 & 24 & & 23 & & 22 & 26 & 25 & & 22 & \\
\hline Well-018 & 23 & 22 & 20 & 24 & 24 & & 24 & & 22 & 20 & 20 & 19 & 21 & & 24 & 23 & 22 & & 22 \\
\hline Well-021 & & 25 & 25 & & 24 & 21 & 23 & 24 & 20 & 23 & 28 & & 20 & 25 & 21 & & 22 & & 25 \\
\hline Well-022 & 24 & 22 & & 21 & & 21 & 20 & 22 & 25 & & 24 & & & 26 & 20 & 20 & & 24 & 27 \\
\hline Well-023 & 24 & & 22 & 21 & 27 & 25 & 23 & 25 & 25 & & 22 & 23 & 30 & 18 & 25 & 23 & 20 & & 25 \\
\hline Well-024 & 20 & 26 & 19 & 23 & 23 & 26 & & 21 & 22 & 24 & 22 & 23 & 19 & 25 & 24 & 21 & 22 & 23 & \\
\hline Well-025 & 24 & 21 & & 22 & 21 & & 21 & 19 & 25 & 23 & 28 & 23 & 23 & 25 & & 25 & & 24 & 25 \\
\hline Well-026 & 21 & 18 & & 24 & 25 & & 24 & 22 & 20 & 23 & 21 & 21 & 26 & 23 & 20 & 25 & 24 & 20 & 24 \\
\hline Well-027 & 25 & 23 & & 24 & 25 & 22 & 27 & & 22 & 26 & & 22 & 21 & 23 & 22 & & 26 & 23 & 19 \\
\hline Well-028 & 25 & & 22 & 23 & 25 & 27 & 23 & 21 & 23 & & 24 & 18 & 22 & & 23 & 20 & 22 & & 25 \\
\hline Well-029 & 24 & 25 & & 19 & 18 & 21 & 22 & 18 & & 21 & 25 & 21 & 23 & & 22 & 25 & 23 & 24 & 27 \\
\hline Well-030 & & 20 & 20 & 27 & & 21 & 26 & 22 & & & 24 & 24 & 24 & 26 & 19 & & 20 & 25 & 24 \\
\hline Well-031 & 24 & 21 & & 21 & & 23 & & 21 & & 22 & 24 & 21 & 23 & 22 & & 21 & 20 & 19 & 25 \\
\hline Well-032 & 18 & 19 & 26 & 25 & 20 & 19 & 27 & 20 & & 22 & 22 & 25 & 25 & & 24 & 23 & & 17 & 24 \\
\hline Well-033 & 27 & 24 & 23 & 22 & & 22 & 22 & & 27 & & 21 & 18 & 21 & 18 & & 22 & 25 & 24 & 23 \\
\hline
\end{tabular}




\section{Importing data into IMagine software}

After generating the data from numerical reservoir simulation, then the data was imported into IMagine software. As shown in Figure 21 the static and dynamic datasets were imported into "Well-Based Data" and oil, gas, and water production datasets were imported into "Production Rate Data”. The dynamic and production rate data from 01/31/1995 to $12 / 31 / 2014$ were only imported into IMagine software and the last two years were not introduced into the software at all in order to test the TDM predictions with the result of numerical reservoir simulation data. The timelines used for modeling and history matching of the top-down model, blind history matching, and forecasting are shown in Figure 22
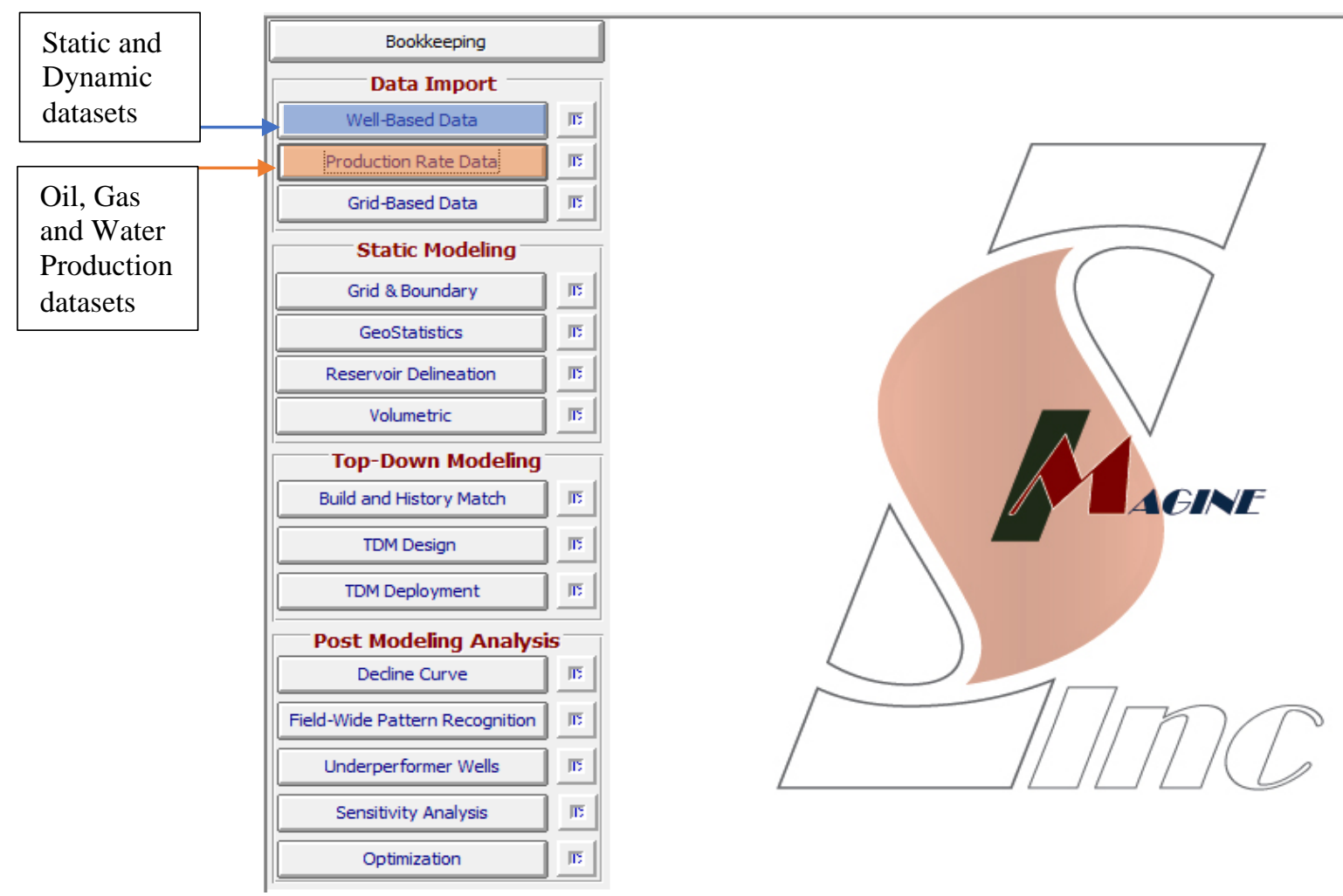

Figure 21: Importing the data 


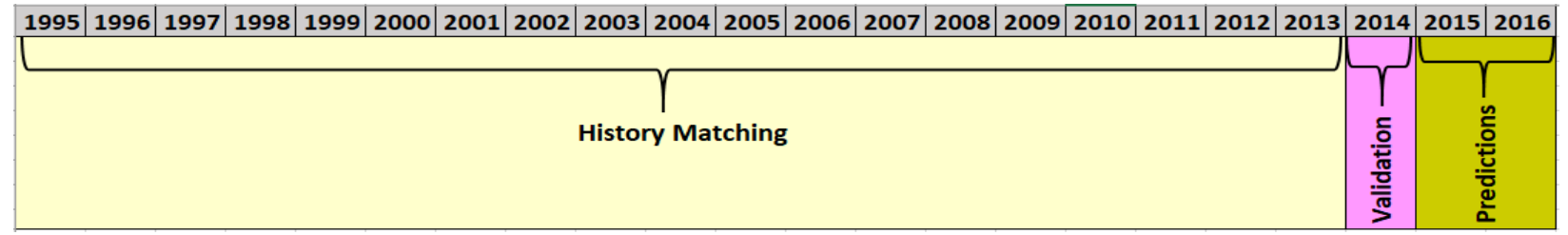

Figure 22: History Matching strategy

\section{Static Modeling}

In this section static modeling that includes grid and boundary, geo-statistics, reservoir delineation and volumetric were performed before proceeding to the Top-Down Modeling section. Reservoir grid size and reservoir boundary were manually adjusted as shown in Figure 23. In geo-statistics section, the models for both static and dynamic attributes were created with the application of inverse distance weighing method. Moreover, the reservoir delineation that includes the drainage area calculations were performed by using the Voronoi technique delineation of the created boundary. Lastly, the volumetric calculations were generated.

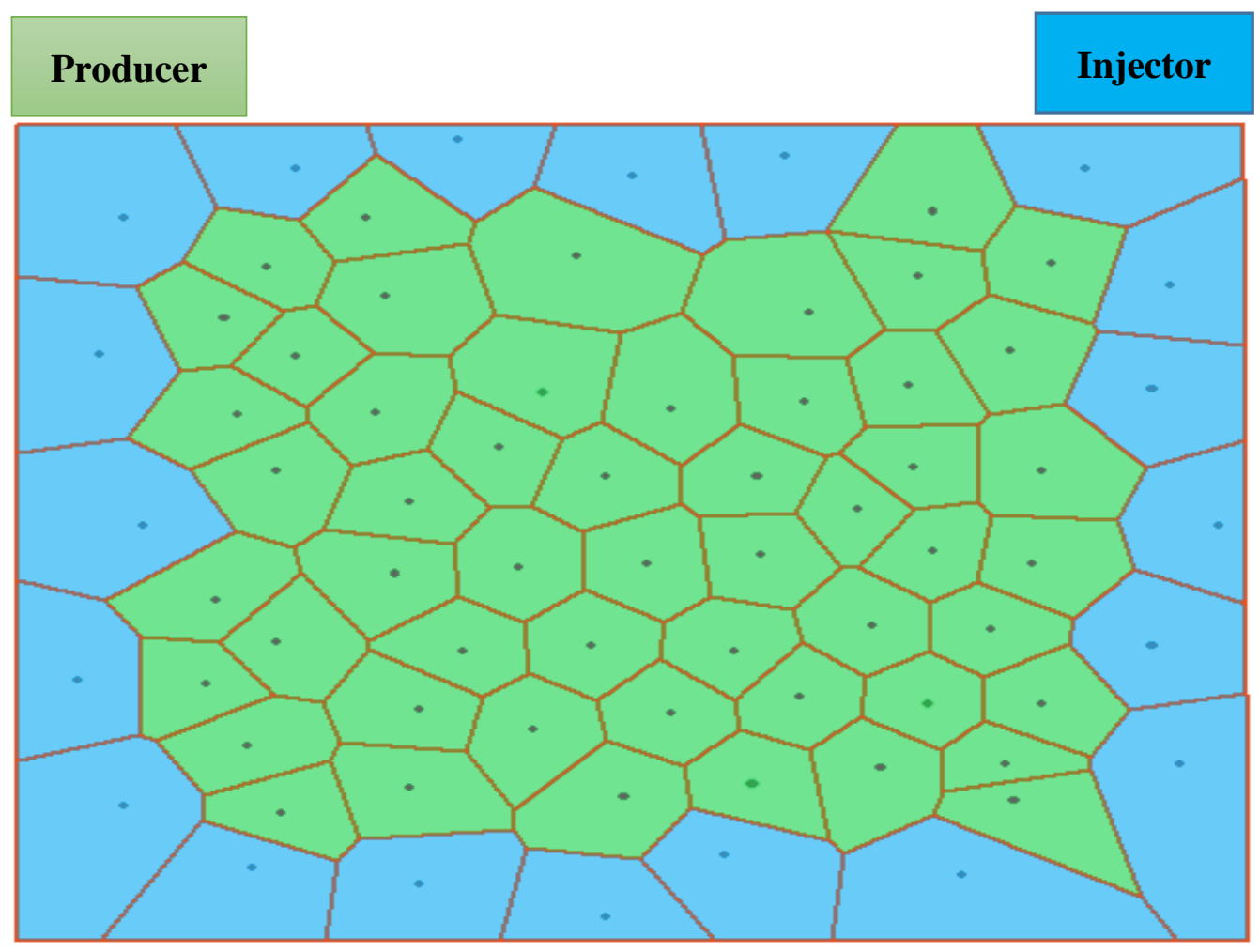

Figure 23: Reservoir Boundary 


\section{Top-Down Modeling: (Model Training and History Matching)}

Build and History match section includes three steps as shown in Figure 24. The first step is the design and status where the model (output) is created, then the second step is the attribute selection and the last step is to generate a comprehensive dataset, which is also known as a Spatio-Temporal database. In Build and History match section the outputs (reservoir pressure, water saturation, oil production, gas production, and water production) were modeled using different attributes. Figure 25 shows the sequences of the outputs (Top-Down Models) that were modeled. In this figure, the static data from the spatio-temporal database along with dynamic data (mainly operational constraints) from the spatio-temporal database at time (t) are needed (as well as the "Reservoir Pressure" at time t -1) to generate the "Reservoir Pressure" at time (t) for all the wells in the asset. Next, static data along with dynamic data at time (t) (mainly operational constraints), as well as recently calculated reservoir pressure at time (t), are required as input to the data-driven water saturation model (as well as the water saturation at time $t-1)$ in order to calculate water saturation at time ( $t$ ) for all the wells in the asset. Similarly, to calculate the production rates (Oil $\rightarrow$ Gas $\rightarrow$ Water) at each well at time (t), static data along with dynamic data from time ( $\mathrm{t}$ ) as well as recently calculated reservoir pressure and water saturation at time ( $\mathrm{t}$ ) (along with production rates from time $\mathrm{t}-1$ ) are required to be used in the data-driven production rate model.

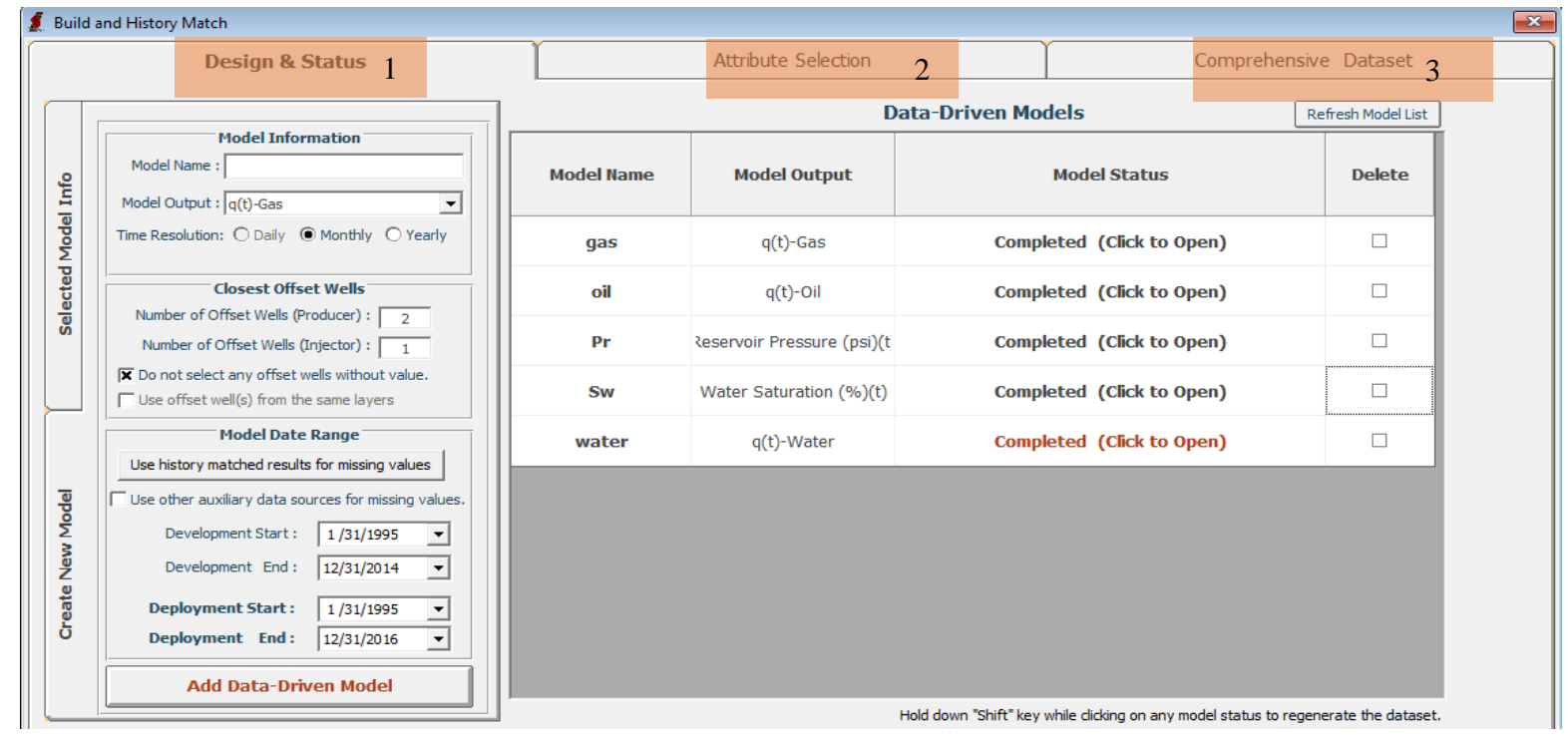

Figure 24: Build and History Match 


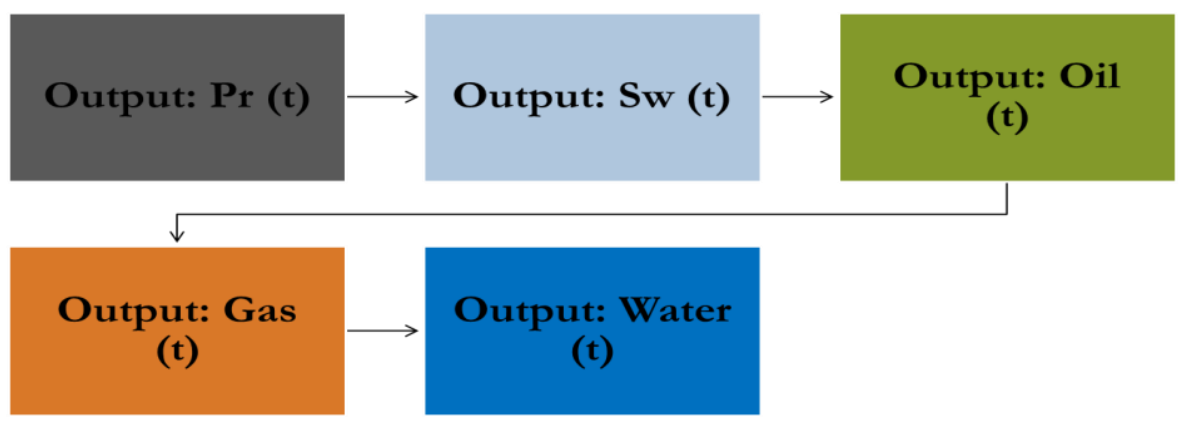

Figure 25: Sequences of Top-Down Models (Output) design

Before creating the spatio-temporal database, different attributes were selected for each output in order to perform the Top-Down Modeling as shown in Figure 26. The green symbol means the attribute has been selected for TDM development and the red symbol means the attribute has not been selected for TDM development. Only the data (dynamic and static data) for two offset producers and one offset injector along with the focal data were used in building the TDM. Once the attributes are selected, the Spatio-Temporal database was created for the five models.

\begin{tabular}{|c|c|c|c|c|c|c|c|c|c|c|c|c|c|c|c|}
\hline \multirow{3}{*}{ Item } & \multirow{3}{*}{ Data } & \multirow[b]{2}{*}{ Parameters } & \multicolumn{5}{|c|}{ Model } & \multirow{3}{*}{ Item } & \multirow{3}{*}{ Data } & \multirow[b]{2}{*}{ Parameters } & \multicolumn{5}{|c|}{ Model } \\
\hline & & & $\operatorname{Pr}(t)$ & Sv (t) & Oil (t) & Gas (t) & Water $(\mathrm{t})$ & & & & $\operatorname{Pr}(t)$ & Sv (t) & Oil (t) & Gas I & dater $(\mathrm{t})$ \\
\hline & & Time & $\checkmark$ & $\checkmark$ & $\checkmark$ & $\checkmark$ & $\checkmark$ & & & Time & $\checkmark$ & $\checkmark$ & $\checkmark$ & $\checkmark$ & $\checkmark$ \\
\hline \multirow{25}{*}{ 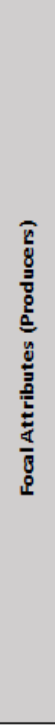 } & \multirow{3}{*}{ Well Location } & XILongitude & $\checkmark$ & $\checkmark$ & $v$ & $\checkmark$ & $\checkmark$ & \multirow{23}{*}{$\frac{0}{8}$} & \multirow{9}{*}{$\begin{array}{l}\text { Well Location } \\
\text { Static Data }\end{array}$} & Distance (t) & $\checkmark$ & $\checkmark$ & $v$ & $\checkmark$ & $\checkmark$ \\
\hline & & YILatitude & $v$ & 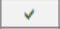 & $\mathrm{v}$ & $\checkmark$ & $\checkmark$ & & & Initial Sv \% & $x$ & $x$ & $x$ & $\mathrm{x}$ & $x$ \\
\hline & & Drainage Area & $\checkmark$ & $\checkmark$ & $\checkmark$ & $\checkmark$ & $\checkmark$ & & & Completion (ft) & $\mathrm{x}$ & $\mathrm{x}$ & $\checkmark$ & $\mathrm{x}$ & $\mathrm{x}$ \\
\hline & \multirow{8}{*}{ Static Data } & Initial Sv \% & $\checkmark$ & $\checkmark$ & $\checkmark$ & $\checkmark$ & $\checkmark$ & & & Pay Thickness & $\checkmark$ & $\checkmark$ & $\checkmark$ & $\checkmark$ & $\checkmark$ \\
\hline & & Completion (ft) & $\checkmark$ & $\checkmark$ & $\checkmark$ & $\checkmark$ & $\checkmark$ & & & Porosity \% & $\checkmark$ & $\checkmark$ & $\checkmark$ & $\checkmark$ & $\checkmark$ \\
\hline & & Pay Thickness & $\checkmark$ & $\checkmark$ & $\checkmark$ & $\checkmark$ & $\checkmark$ & & & Permeability md & $\checkmark$ & $\checkmark$ & $\checkmark$ & $\checkmark$ & $\checkmark$ \\
\hline & & Porosity \% & $\checkmark$ & $\checkmark$ & $\checkmark$ & $\checkmark$ & $\checkmark$ & & & Porh(1-Sv) & $\mathrm{x}$ & $x$ & $x$ & $\mathrm{x}$ & $\mathrm{x}$ \\
\hline & & Permeability md & $\checkmark$ & $\checkmark$ & $\checkmark$ & $\checkmark$ & $\checkmark$ & & & TYD (ft) & $\checkmark$ & $\checkmark$ & $\checkmark$ & $\checkmark$ & $\checkmark$ \\
\hline & & Porh(1-Sv) & $\checkmark$ & $\checkmark$ & $\checkmark$ & $\checkmark$ & $\checkmark$ & & & Top (ft) & $\mathrm{x}$ & $\mathrm{x}$ & $\checkmark$ & $\mathrm{x}$ & $\mathrm{x}$ \\
\hline & & TVD (ft) & $\checkmark$ & $\checkmark$ & $\checkmark$ & $\checkmark$ & $\checkmark$ & & \multirow{8}{*}{ Dynamic Data } & FBH Pressure (psi) (t) & $\checkmark$ & $\checkmark$ & $\checkmark$ & $\checkmark$ & $\checkmark$ \\
\hline & & Top (ft) & $\checkmark$ & $\checkmark$ & $\checkmark$ & $\checkmark$ & $\checkmark$ & & & FBH Pressure (psi) (t-1) & $\checkmark$ & $\checkmark$ & $\checkmark$ & $\checkmark$ & $\checkmark$ \\
\hline & \multirow{8}{*}{ Dynamic Data } & FBH Pressure (psi) (t) & $\checkmark$ & $\checkmark$ & $\checkmark$ & $\checkmark$ & $\checkmark$ & & & Days of Production (Day) ( $t$ ) & $\checkmark$ & $\checkmark$ & $\checkmark$ & $\checkmark$ & $\checkmark$ \\
\hline & & FBH Pressure (psi) (t-1) & $\checkmark$ & $\checkmark$ & $\checkmark$ & $\checkmark$ & $\checkmark$ & & & Days of Production (Day) ( $t-1)$ & $\checkmark$ & $\checkmark$ & $\checkmark$ & $\checkmark$ & $\checkmark$ \\
\hline & & Days of Production (Day) (t) & $\checkmark$ & $\checkmark$ & $\checkmark$ & $\checkmark$ & $\checkmark$ & & & Reservoir Pressure (psi) (t) & $\mathrm{x}$ & $\mathrm{x}$ & $\mathrm{x}$ & $\mathrm{x}$ & $\mathrm{x}$ \\
\hline & & Days of Production (Day) $(t-1)$ & $\checkmark$ & $\checkmark$ & $\checkmark$ & $\checkmark$ & $\checkmark$ & & & Reservoir Pressure (psi) ( $t-1)$ & $\checkmark$ & $\checkmark$ & $\checkmark$ & $\mathrm{v}$ & $\checkmark$ \\
\hline & & Reservoir Pressure (psi) ( $t]$ & $\checkmark$ & $\checkmark$ & $\checkmark$ & $\checkmark$ & $\checkmark$ & & & Yater Saturation $(\%)[t]$ & $\mathrm{x}$ & $x$ & $\mathrm{x}$ & $\mathrm{x}$ & $\mathrm{x}$ \\
\hline & & Reservoir Pressure (psi) (t -1) & $\checkmark$ & $\checkmark$ & $\checkmark$ & $\checkmark$ & $\checkmark$ & & & Vater Saturation (\%) (t-1) & $\checkmark$ & $\checkmark$ & $\checkmark$ & $\checkmark$ & $\checkmark$ \\
\hline & & Vater Saturation $[\%](t)$ & $\mathrm{x}$ & $\checkmark$ & $\checkmark$ & $\checkmark$ & $\checkmark$ & & \multirow{6}{*}{ Rate } & $q(t)$ Oil & $\mathrm{x}$ & $\mathrm{x}$ & $\mathrm{x}$ & $\mathrm{x}$ & $x$ \\
\hline & & Yater Saturation $(\%)(t-1)$ & $\checkmark$ & $\checkmark$ & $\checkmark$ & $\checkmark$ & $\checkmark$ & & & $\mathrm{q}(\mathrm{t}-1)$ Oil & $\checkmark$ & $\checkmark$ & $\checkmark$ & $\checkmark$ & $\checkmark$ \\
\hline & \multirow{6}{*}{ Rate } & $q(t)$ Oil & $\mathrm{x}$ & $x$ & $\checkmark$ & $\checkmark$ & $\checkmark$ & & & $q(t)$ Gas & $x$ & $x$ & $x$ & $x$ & $x$ \\
\hline & & $q(t-1)$ Oil & $\checkmark$ & $\checkmark$ & $\checkmark$ & $\checkmark$ & $\checkmark$ & & & $q(t-1)$ Gas & $\checkmark$ & $\checkmark$ & $\checkmark$ & $\checkmark$ & $\checkmark$ \\
\hline & & $q(t)$ Gas & $x$ & $x$ & $x$ & $\checkmark$ & $\checkmark$ & & & $q(t)$ Yater & $\mathrm{x}$ & $\mathrm{x}$ & $x$ & $\mathrm{x}$ & $\mathrm{x}$ \\
\hline & & $q(t-1)$ Gas & $\checkmark$ & $\checkmark$ & $\checkmark$ & $\checkmark$ & $\checkmark$ & & & $q(t-1)$ Vater & $\checkmark$ & $\checkmark$ & $\checkmark$ & $\checkmark$ & $\checkmark$ \\
\hline & & $\mathbf{q}(t)$ Yater & $x$ & $x$ & $x$ & $x$ & $\checkmark$ & \multirow{2}{*}{$\begin{array}{c}\text { Offset } \\
\text { Attributes } \\
\text { (Injectors) }\end{array}$} & \multirow{2}{*}{$\begin{array}{l}\text { Well Location } \\
\text { Dynamic Data }\end{array}$} & Distance & $\checkmark$ & $\checkmark$ & $\checkmark$ & $\checkmark$ & $\checkmark$ \\
\hline & & $\mathbf{q}(t-1)$ Vater & $\checkmark$ & $\checkmark$ & $\checkmark$ & $\checkmark$ & $\checkmark$ & & & Vater Injection (t) & $\checkmark$ & $\checkmark$ & $\checkmark$ & $\checkmark$ & $\checkmark$ \\
\hline
\end{tabular}

Figure 26: The attributes that have been selected for building the TDM 
Figure 27 is an example of Spatio-Temporal database that has been created for oil production model. Once the Spatio-Temporal database is created, then data cleaning are performed by removing the zero values of oil production first, followed by assigning zero to the missing values and after that sorting by well and then by date. The number of total cases (records) were 6572 after excluding the oil that has zero production from the Spatio-Temporal dataset. Table 2 shows the number of total cases that has been assigned for training, calibration and validation. In this thesis, the Top-Down modeling was done using resolution in time. Therefore, Multi random portioning method was selected and the last year 2014 that has 509 records were assigned as a blind validation and $85 \%$ of the total cases excluding the 509 records were assigned as a training dataset and $15 \%$ of the total cases excluding the 509 records were assigned as a calibration dataset. Next, the neural network is trained, calibrated and validated in a satisfactory manner, the results are evaluated against the actual data (data generated by numerical reservoir simulation) in order to see if the top-down model is able to match the production history for all the wells in the field (history matching). The result of the training, calibration and validation will be presented in the next chapter.

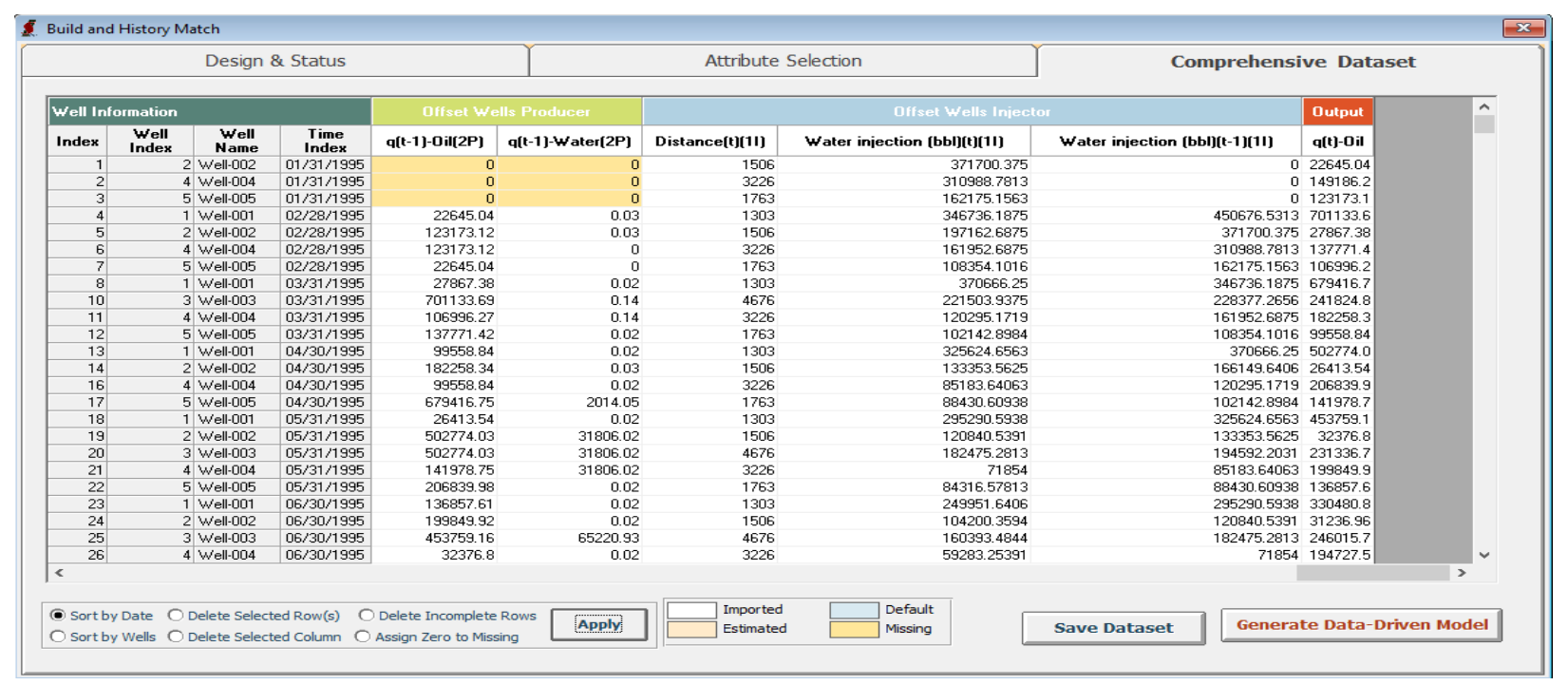

Figure 27: Example of Spatio-Temporal database for Oil

Table 2: Number of cases in training, calibration and validation

\begin{tabular}{l|l|l|l|l}
\hline Total Cases & Validation (year 2014) & Total cases excluding the last year & Training & Calibration \\
\hline 6572 & 509 & 6063 & 5154 & 909 \\
\hline
\end{tabular}




\section{Forecasting}

Once the TDM is developed (trained, calibrated and verified) in a satisfactory manner from 1995 to 2014, then the developed models will be deployed in the forecast mode in order to estimate the future production of oil, gas, and water production and test them against the data that was generated by the numerical reservoir simulation. However, it is very important to add the operational constrains of the years that will be predicted before deployment or forecasting. Therefore, the operational constrains data were added into the TDM deployment section as shown in Figure 28. This data only includes days of production, FBHP and water injection from $01 / 01 / 2015$ to $12 / 31 / 2016$. Once the data was updated, then TDM was deployed. The forecasting results will be presented in the next chapter.

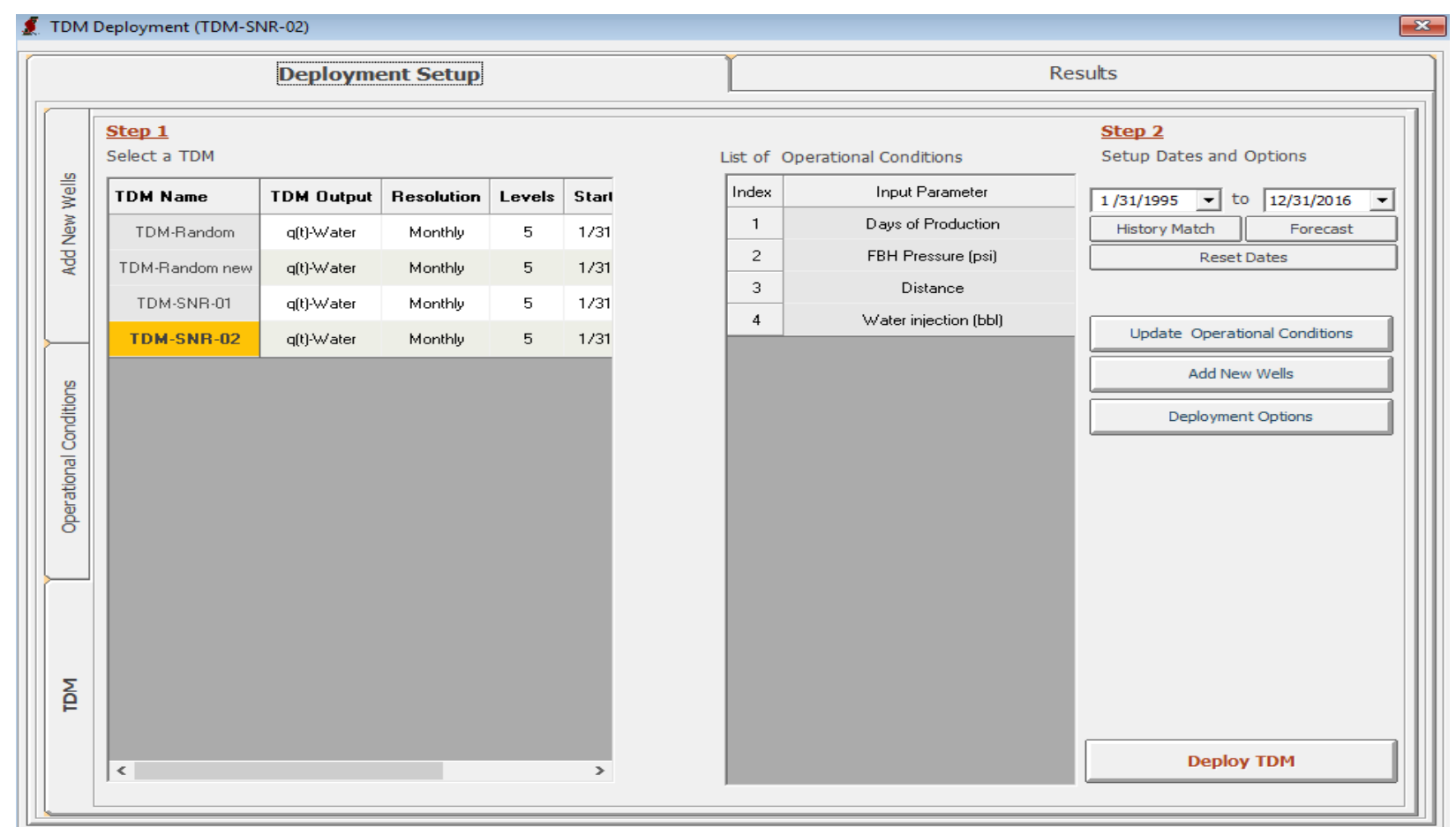

Figure 28: TDM deployment section 


\section{CHAPTER IV}

\section{RESULT}

\subsection{Training, Calibration and Validation Results}

The results of the developed (trained, calibrated and validated) TDM for reservoir pressure, water saturation, oil production, gas production and water production are illustrated in this section. After multiple of trial and error, the best model was selected based on the obtained $\mathrm{R}^{2}$ of the three sets (Training, Calibration and Verification). As shown in the Figures 29 and 30, it can be seen that the three sets (Training, Calibration and Verification) for the five models have a pretty good pattern. That means that the TDM is trained, calibrated and validated in a satisfactory manner. Therefore, these models (reservoir pressure, water saturation, oil production, gas production and water production) are used to perform the predictions. The $\mathrm{R}^{2}$ result for the training, calibration and validation datasets can be summarized in table 3 .
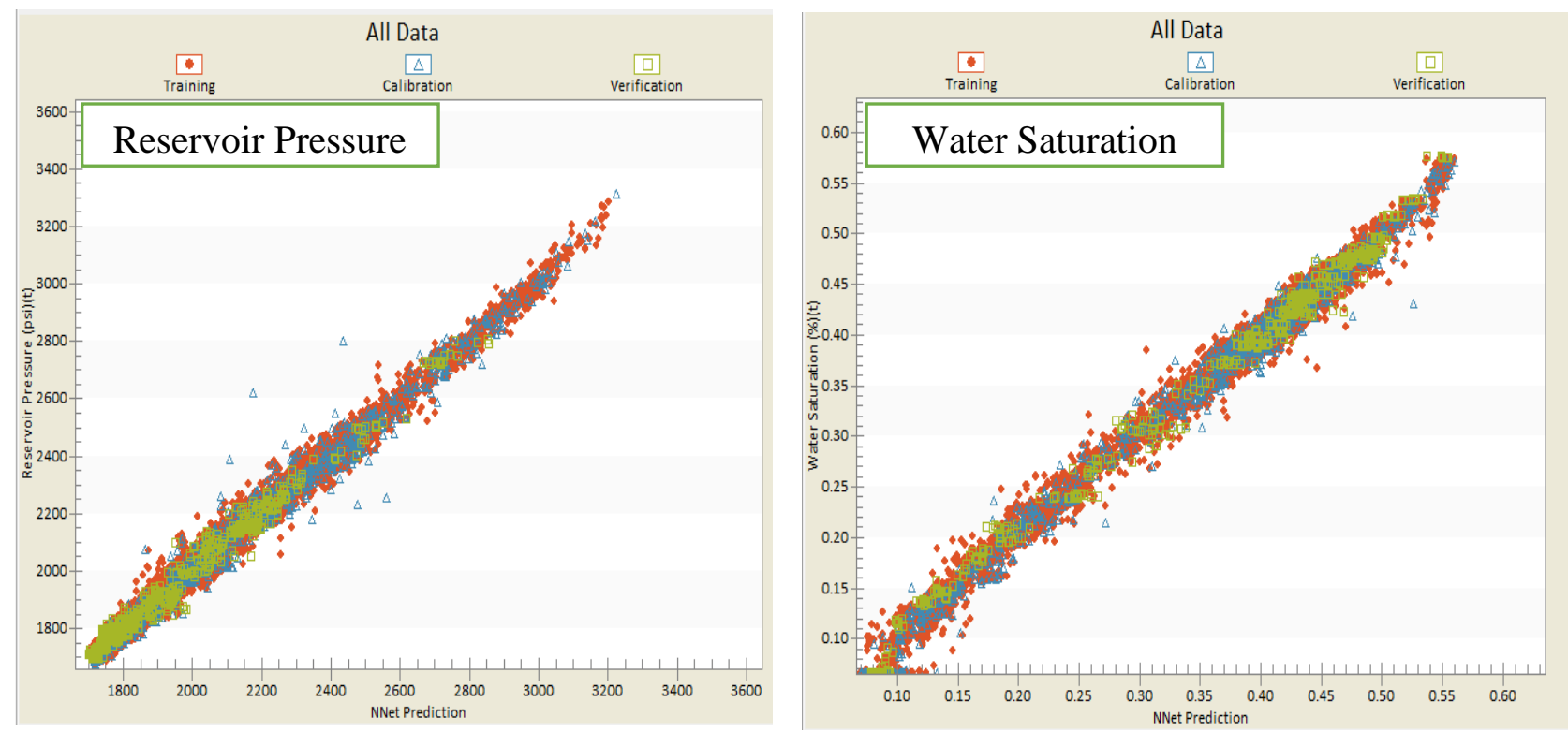

Figure 29: Results of training, calibration validation for Reservoir pressure and water saturation 

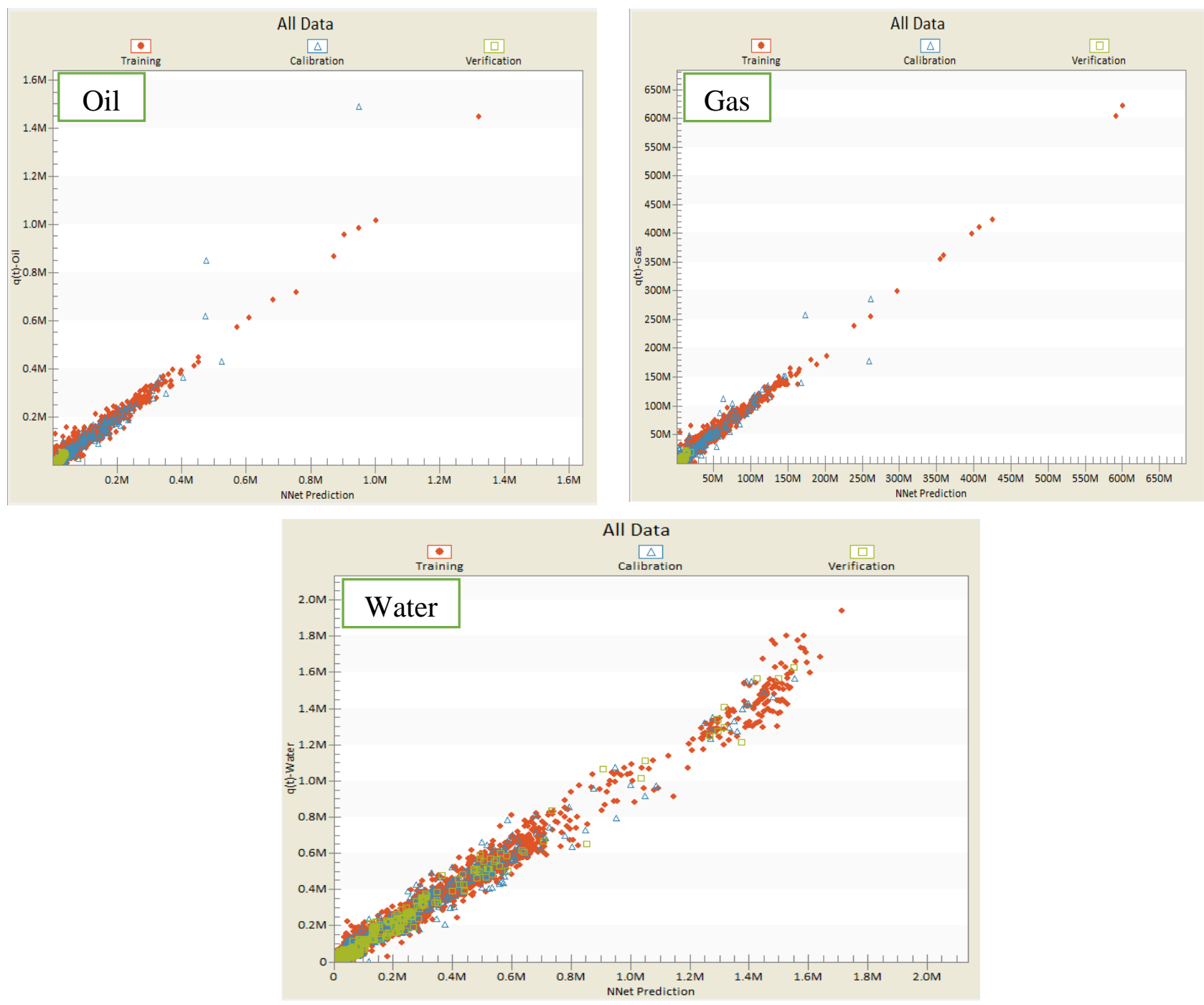

Figure 30: Results of Training, Calibration and Validation for Oil, Gas and Water

Table 3: The $R^{2}$ result for Training, Calibration and Validation datasets

\begin{tabular}{l|l|l|l}
\hline \multicolumn{1}{c|}{ Dataset } & Training & Calibration & Validation \\
\hline Reservoir Pressure & 0.988 & 0.98 & 0.982 \\
\hline Water Saturation & 0.992 & 0.99 & 0.993 \\
\hline Oil Production & 0.978 & 0.902 & 0.821 \\
\hline Gas Production & 0.985 & 0.94 & 0.831 \\
\hline Water Production & 0.986 & 0.978 & 0.984 \\
\hline
\end{tabular}




\subsection{Top-Down Model Results (History Matching and TDM Predictions)}

The results of training and history matching, blind history matching, and forecasting of the top-down model are shown in Figures 31 through 34. Each of these figures includes detailed history matching and forecasting of four individual wells (Well-006, Well-009, Well-021 and Well-037). In each of the figures, three graphs are shown. In all three graphs, the $\mathrm{x}$-axis is time (date) that extends from the initial production date to the forecast time of 2016. The time in the $\mathrm{x}$ axis is divided into three segments identifying the period of time used for training and history matching of the top-down model (1995 to 2013 - before the bink line), the period of time used for blind history matching (2013 to 2014 - between pink line and olive line), and the period of time used for forecasting (2015 and 2016-after olive line). In each of the graphs in Figures 31 through 34, actual data are shown using green dots, while the results from the top-down model are shown as solid grey lines. In these figures, the graph at the top shows the oil production as a function of time. The middle graph shows the gas production as a function of time. The bottom graph shows water production as a function of time. These figures illustrated a pretty good history matching. Furthermore, it clearly shows that TDM is quite powerful when it comes to history matching past production measurements (actual data) from every individual well in the field. As demonstrated in Shahab's book (Mohaghegh, Data-Driven Reservoir Modeling, 2017), the top-down model does this by learning the reservoir and well-production behaviour using the internal correlations that it builds between static and dynamic parameters with production from each well, taking into account production constraints and injection and production from offset wells. This is accomplished one record at a time and then is put together to present production from a well and ultimately production from the entire field, as shown in Figure 35. In this figure the entire reservoir (entire field) is illustrated along with the active wells. The accuracy of the top-down model during the blind history match, as demonstrated in Figures 31 through 35 is an impressive accomplishment, especially when it is compared with results from numerical reservoir simulation. The comparison of TDM result with numerical reservoir simulation result for the four wells will be demonstrated next section. In this section only the result of four wells out of 53 wells are presented. The results of the rest of the wells can be found in the appendix. 


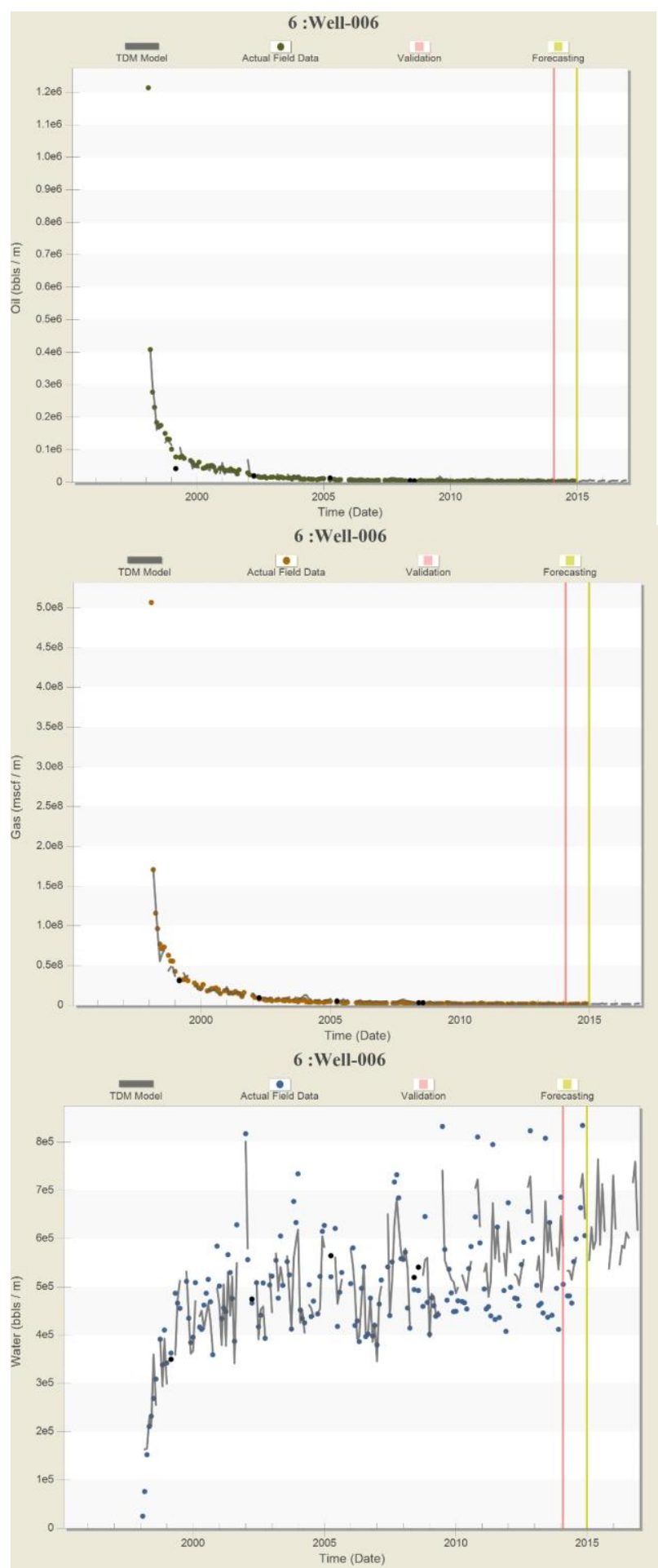

Figure 31: Complete History Matching and Prediction result for well-006

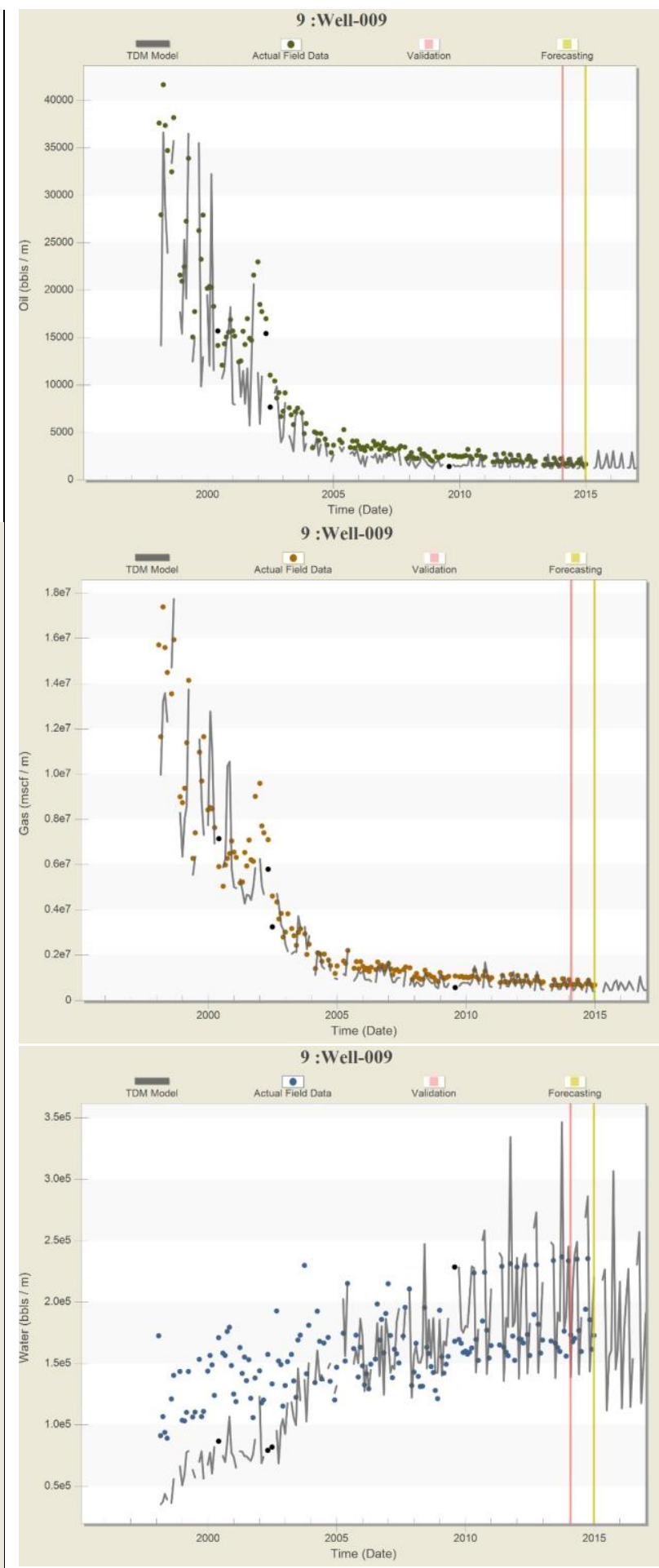

Figure 32: Complete History Matching and Prediction result for well-009 

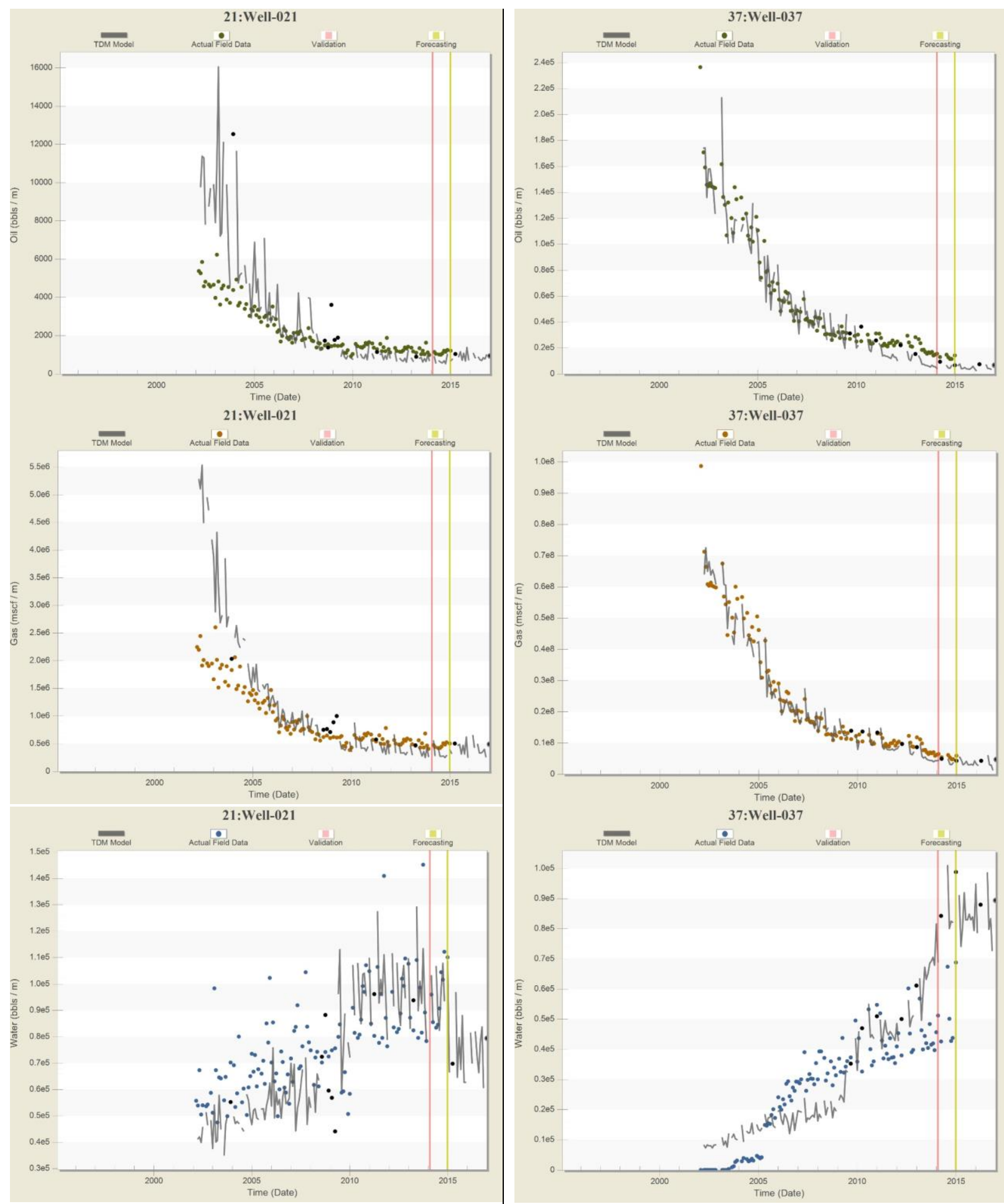

Figure 33: Complete History Matching and Prediction result for well-021

Figure 34: Complete History Matching and Prediction result for well-037 


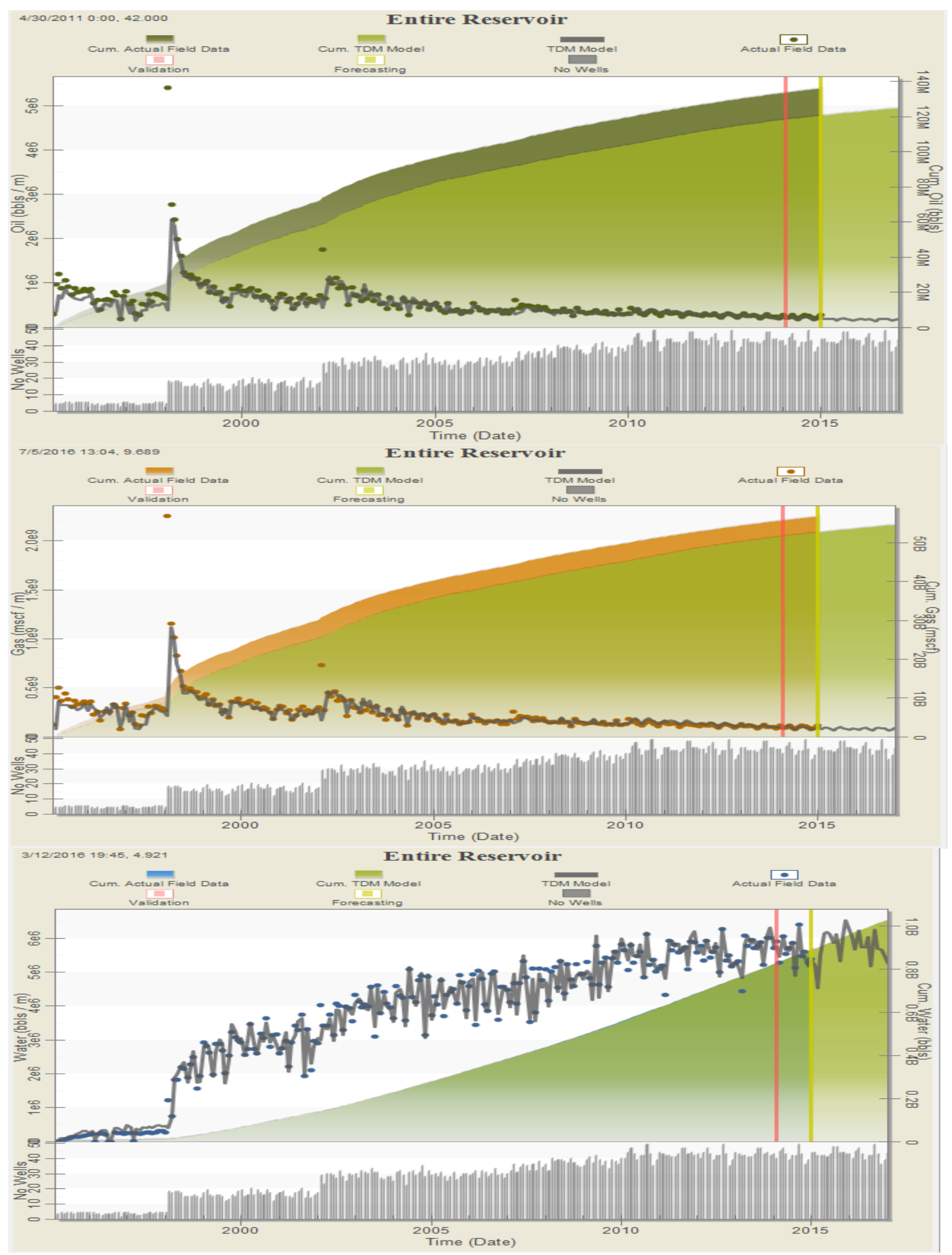

Figure 35: Complete History Matching and Prediction results for the entire field (reservoir) 


\subsection{Confirming Results of TDM Predictions using Numerical Reservoir Simulation data}

The objective of this thesis is to confirm the results of Data-Driven Reservoir Modeling which is also known as a Top-Down Modeling (TDM) using the data generated from the Numerical Reservoir Simulation. In this section the result of the TDM predictions (2015 and 2016) are tested against the synthetic data. As mentioned in Chapter 3 "methodology" the data for the last two years (2015 and 2016) that has been generated by numerical reservoir simulation were not introduced to the Data-Driven reservoir modeling software (IMagine). That means the TDM will predict the last two years that has never seen before. Therefore, based on the Artificial Intelligence and Machine Learning and the available data from 1995 to 2014, the last two years were predicted. In order to do the comparison, the results of training and history matching, blind history matching, and forecasting of the top-down model were exported from IMagine software. Then, the results of the TDM were plotted against the results of numerical reservoir simulation using Python as shown in Figures 36 through 39. Each of these figures includes detailed history matching and forecasting of four individual wells (Well-006, Well-009, Well-021 and Well-037). In each of the figures, three graphs are shown. In all three graphs, the $\mathrm{x}$-axis is time (date) that extends from the initial production date to the forecast time of 2016. The time in the x-axis is divided into three segments identifying the period of time used for training and history matching of the top-down model (1995 to 2013 - before the bink line), the period of time used for blind history matching (2013 to 2014 between pink line and olive line), and the period of time used for forecasting (2015 and 2016 after olive line). In each of the graphs in Figures 31 through 34, actual data are shown using green dots, while the results from the top-down model are shown as solid grey lines. In these figures, the graph at the top shows the oil production as a function of time. The middle graph shows the gas production as a function of time. The bottom graph shows water production as a function of time. Based on the graphs below, the result of the TDM predictions of the last two years (2015 and 2016) for the oil production, gas production and water production has reflected the same result as numerical reservoir simulation. Therefore, we can clearly say data-driven reservoir modeling is a reliable and promising technology and it can be trusted and used with real field measurements data. 

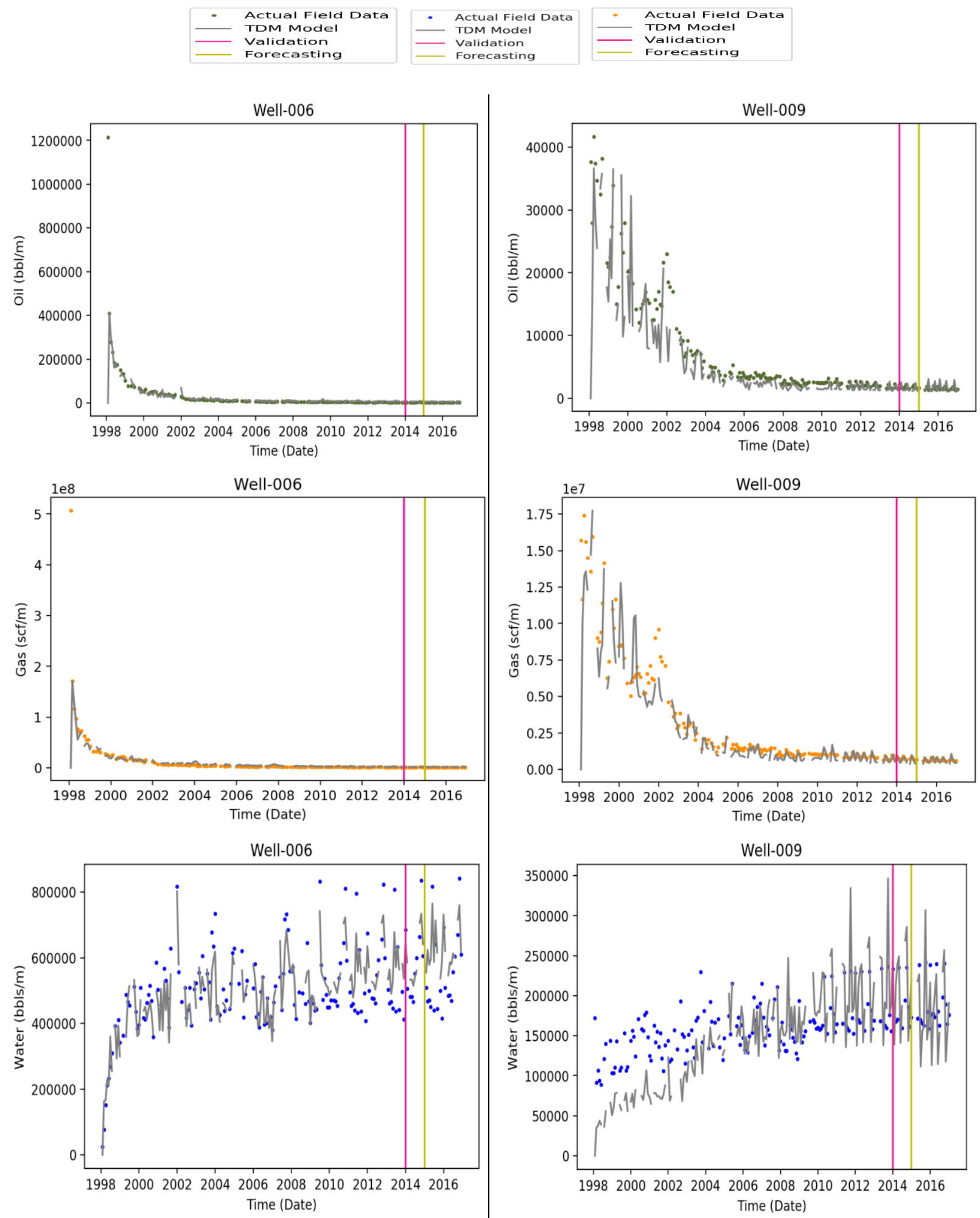

Figure 36:TDM result versus numerical reservoir simulation result for well-006

Figure 37: TDM result versus numerical reservoir simulation result for well-009 

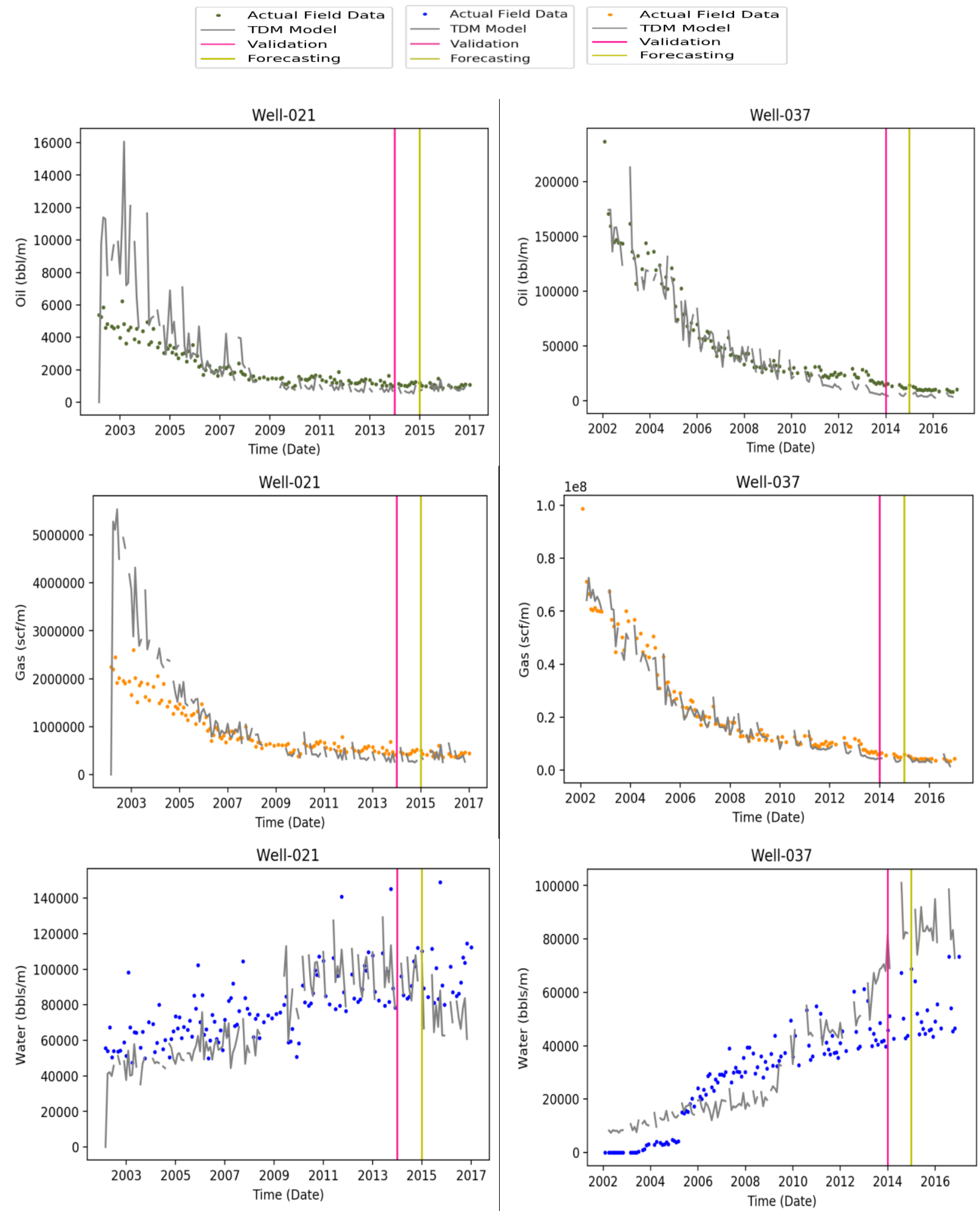

Figure 38: TDM result versus numerical reservoir simulation result for well-021

Figure 39: TDM result versus numerical reservoir simulation result for well-037 


\section{CHAPTER V}

\section{CONCLUSION}

\subsection{Conclusion}

In order to efficiently develop and operate a petroleum reservoir, it is important to have a reservoir model. Nowadays, the only technique that is accepted and is being used in our industry is the reservoir numerical simulation. However, this technology is not accurate because it does not use the large amount of the available data from the mature fields. Therefore, data driven reservoir modeling technology, also known as Top-Down Model (TDM), provides a complete alternative to the numerical reservoir simulation model and can serve as an appropriate tool for reservoir management. TDM combines all field measurements into a comprehensive reservoir model to predict the production from each well in a field with multiple wells and then TDM is used to predict the well performance for the future of the field.

There are many opinions, speculations and criticism when we do not use the physics-based approach. Therefore, in this thesis synthetic data generated from a numerical reservoir simulation model was used for the development of a data-driven reservoir modeling to confirm the capabilities of TDM technology.

TDM was developed (trained, calibrated and validated) and history matched using the data generated by a complex numerical reservoir simulation model. The result clearly shows that TDM is quite powerful when it comes to history matching past production measurements (actual data) from every individual well in the field. Furthermore, predictions were made using the developed TDM and are tested against the data that was generated by the numerical reservoir simulation. It has been noticed that the result of the TDM predictions of the last two years (2015 and 2016) for the oil production, gas production and water production has reflected and confirmed to be almost the same result as numerical reservoir simulation. Therefore, we can clearly say data-driven reservoir modeling using artificial intelligence and machine learning is a reliable and promising technology and it can be trusted and used with real field measurements data. 


\section{REFERENCES}

Gomez, Y., Khazaeni, Y., Mohaghegh, S. D., \& Gaskari, R. (2009, January). Top Down Intelligent Reservoir Modeling. In SPE Annual Technical Conference and Exhibition. Society of Petroleum Engineers .

Maysami, M., Gaskari, R., \& Mohaghegh, S. D. . (2013, September). Data Driven Analytics in Powder River Basin, WY. In SPE Annual Technical Conference and Exhibition. Society of Petroleum Engineers.

Mohaghegh, S. D. (2011, January). Reservoir Simulation and Modeling Based on Pattern Recognition. In SPE Digital Energy Conference and Exhibition. Society of Petroleum Engineers.

Mohaghegh, S. D. (2017). Data-Driven Reservoir Modeling. Society of Petroleum Engineers.

Mohaghegh, S. D. (2017). Shale Analytics. Springer, Cham.

Mohaghegh, S. D., Al-Mehairi, Y., Gaskari, R., Maysami, M., \& Khazaeni, Y. (October, 2014). Data-driven reservoir management of a giant mature oilfield in the Middle East. In SPE annual technical conference and exhibition. Society of Petroleum Engineers.

Shahab D. Mohaghegh, S. Alireza Haghighat, Vida Gholami \& David Moreno,. (April 2014). Production Analysis of a Niobrara Field Using Intelligent Top-Down Modeling. In SPE Western North American and Rocky Mountain Joint Meeting. Society of Petroleum Engineer.

Shahkarami, A., Mohaghegh, S. D., Gholami, V., \& Haghighat, S. A. (2014, April). Artificial Intelligence (AI) Assisted History Matching . In SPE Western North American and Rocky Mountain Joint Meeting. Society of Petroleum Engineers . 